DOI: $10.1002 /$ ((please add manuscript number))

Article type: Review

\title{
Defect and Contact Passivation for Perovskite Solar Cells
}

Erkan Aydin, Michele De Bastiani, and Stefaan De Wolf*

King Abdullah University of Science and Technology (KAUST), KAUST Solar Center (KSC), Physical Sciences and Engineering Division (PSE), Thuwal 23955-6900, Kingdom of Saudi Arabia

E-mail: $\underline{\text { stefaan.dewolf@kaust.edu.sa }}$

Keywords: solar cells, perovskites, contacts, recombination, passivation, hysteresis, stability

Metal-halide perovskites are rapidly emerging as an important class of photovoltaic absorbers that may enable high-performance solar cells at affordable cost. Thanks to the appealing optoelectronic properties of these materials, tremendous progress has been reported in the last few years in terms of power conversion efficiencies of perovskite solar cells (PSCs), now with record values in excess of $23 \%$. Nevertheless, the crystalline lattice of perovskites often includes defects, such as interstitials, vacancies, and impurities; at the grain boundaries and surfaces, dangling bonds can also be present, which all contribute to non-radiative recombination of photo-carriers. On device level, such recombination undesirably inflates the open-circuit voltage deficit, acting thus as a significant roadblock towards the theoretical efficiency limit of $30 \%$. In this review, we focus on the origin of various voltage-limiting mechanisms in PSCs and discuss possible mitigation strategies. We describe contact passivation schemes and the effect of such methods on the reduction of hysteresis. Furthermore, we elucidate several strategies that demonstrate how passivating contacts can increase the stability of PSCs. Finally, we prioritize the remaining key 
challenges in contact design and present an outlook on how passivating contacts will contribute to further the progress towards market readiness of high-efficiency PSCs.

\section{Introduction}

Perovskite solar cells (PSCs) have gained rapid widespread attention for its promise as a highefficiency photovoltaic (PV) technology; devices now already achieve impressive power conversion efficiencies (PCEs) of more than 23\%. ${ }^{[1]}$ Such performance can largely be attributed to the remarkable optoelectronic properties of perovskites which combine, for instance, a high absorption coefficient with low Urbach energy $\left(E_{0}\right) \cdot{ }^{[2]}$ On device level, a high absorption coefficient enables photocurrents close to the theoretical maximum without the need for complicated light-trapping schemes, whereas a low $E_{0}$ is essential to obtain a low open-circuitvoltage deficit $\mathrm{W}_{\mathrm{OC}}=\mathrm{E}_{\mathrm{g}} / \mathrm{q}-\mathrm{V}_{\mathrm{OC}}$, where $E_{\mathrm{g}}$ is the bandgap, $q$ is the elementary charge, and $V_{O C}$ is the open circuit voltage. ${ }^{[3]}$ Thus far, one of the highest reported $\mathrm{V}_{\mathrm{OC}}$ is $1.24 \mathrm{~V}^{[4]}$ (for a $1.6 \mathrm{eV}$ band gap perovskite absorber), which is below the theoretical value of $1.32 \mathrm{~V}$, obtained when only considering radiative recombination. ${ }^{[5]}$ Similar to other thin-film PV materials such as galliumarsenide (GaAs), copper-indium-gallium-selenide (CIGS), cadmium-telluride (CdTe), perovskite films often feature intrinsic defects, such as interstitials and vacancies, as well as impurities and non-coordinated ions at their grain boundaries and surfaces. Such defects can result in gap states that induce non-radiative recombination of photo-generated carriers. Such recombination undesirably lowers the operating voltages under open circuit as well as maximum power point (MPP) conditions. The latter detrimentally affects the fill factor (FF) of devices and thus their overall power output. The presence of such defects also contributes to hysteresis in the currentvoltage characteristics. To translate the attractive optoelectronic properties of perovskites into higher device performance and to continue progress towards realizing their theoretical PCE limit 
of $30 \%$, further device engineering is therefore essential. In the development of crystalline silicon (c-Si) solar cells, the use of high-quality silicon wafers, combined with effective surface- and contact-passivation strategies pushed experimental operating voltages close to their theoretical limit, ${ }^{[6]}$ and device efficiencies as high as $26.7 \% .{ }^{[7]}$ The performance of other PV technologies, such as CdTe, CIGS and CZTS thin-film solar cells, also benefits from the use of surfacepassivation strategies. ${ }^{[8]}$ Taking inspiration from these improvements, we argue that a deeper understanding of the specific defect physics of perovskites and the use of passivation strategies, combined will lead to performance improvements in PSCs.

In this review, we first consider how unintentional bulk defects may be eliminated by increasing the quality of perovskite crystals. Next, we describe available extrinsic defect-passivation methods to minimize interfacial and grain-boundary (GB) recombination losses. To improve device performance, we focus on surface-passivating materials that can be integrated into the contact stacks of devices without jeopardizing carrier extraction, with an in-depth discussion of their underlying passivation mechanisms. Finally, we correlate passivation schemes with their effect on minimized hysteresis, increased PCE (focusing on $V_{\text {OC }}$ improvement) and enhanced stability. We conclude by highlighting the remaining challenges in contact design that need to be solved and by providing an outlook on how passivating contacts will bring forward the market readiness of highefficiency PSCs.

\section{Role of Defects in Voltage and Hysteresis in Perovskite Solar Cells}

The $V_{\text {OC }}$ of a solar cell is directly related to the splitting of the electron and hole quasi-Fermi levels in its semiconducting absorber (and thus its excess-charge carrier densities, $\Delta n$ and $\Delta p$ ) excited under specific illumination conditions, usually at one sun. In turn, $\Delta n$ (usually, $\Delta n \approx \Delta p$ ) directly 
depends on the effective free-carrier lifetime, $\tau_{\text {eff, }}$ through $\tau_{\text {eff }}=\Delta n / U_{\text {eff, }}$, where $U_{\text {eff }}$ is the effective recombination rate. Notably, $\tau_{\text {eff }}$ is a parameter that is fairly easily experimentally extracted and used to assess the electronic quality of a semiconductor. The fact that $\tau_{\text {eff }}$ can strongly depend on $\Delta n$ underlines the importance of measuring $\tau_{\text {eff }}$ under excitation conditions that are representative for actual device operation, as well as always reporting the $\Delta n$ value at which $\tau_{\text {eff }}$ was measured. As recombination rates are additive in semiconductors, $\tau_{\mathrm{eff}}$ depends in perovskite absorbers on their bulk and surface recombination, according to: ${ }^{[9]}$

$\frac{1}{\tau_{\text {eff }}}=\frac{1}{\tau_{\text {bulk }}}+\frac{1}{\tau_{\text {surf }}}$

In this, the bulk carrier lifetime, $\tau_{\text {bulk }}$, depends on the trap- or defect-induced (also referred to as Shockley-Read-Hall, $\tau_{S R H}$ ) recombination, band-to-band radiative recombination (which is the reciprocal process of photon absorption, $\left.\tau_{\text {rad }}\right)$ and Auger recombination $\left(\tau_{\text {Auger }}\right)$, as follows: ${ }^{[10]}$

$\frac{1}{\tau_{\text {bulk }}}=\frac{1}{\tau_{\text {rad }}}+\frac{1}{\tau_{\text {Auger }}}+\frac{1}{\tau_{S R H}}$

Figure 1a is a representative plot of these different contributions for a perovskite material as a function of $\Delta n$, using data taken from ${ }^{[10]}$. It is seen that SRH recombination dominates $\tau_{\text {bulk }}$ at low carrier injection $\left(\Delta n<\sim 10^{15} \mathrm{~cm}^{-3}\right)$, whereas Auger recombination dominates at high injection $(\Delta n$ $>\sim 10^{18} \mathrm{~cm}^{-3}$ ). In PSCs, the $\mathrm{V}_{\mathrm{OC}}$ conditions under 1-sun illumination reportedly correspond to $\Delta n$ $\sim 10^{16} \mathrm{~cm}^{-3} \cdot{ }^{[5,11]}$ This $\Delta n$ value is comparable to that in high-quality, well passivated, $c$-Si solar cells under similar operating conditions, such as silicon heterojunction solar cells. ${ }^{[12]}$ We remark that $\Delta n$ also strongly depends on the thickness of the absorber; $c$-Si solar cells usually have an absorber thickness $>100 \mu \mathrm{m}$, compared to at most a few hundreds of $\mathrm{nm}$ for perovskites. Therefore, the similar $\Delta n$ value for the two technologies may be surprising, but is explained by silicon solar 
cells' much higher $\tau_{\text {eff }}$ values, usually well above $100 \mu$ s (compared to $<1 \mu$ s for perovskites), ${ }^{[10,}$ 13] a consequence of the indirect bandgap of $c$-Si. Figure 1a shows that PSCs are often rather limited by SRH (or radiative) recombination than by Auger recombination under standard solar cell operating conditions (approximately $10^{14} \mathrm{~cm}^{-3}<\Delta n<10^{16} \mathrm{~cm}^{-3}$ ), which is explained by the relatively small Auger recombination rate constants; e.g., about $10^{-28} \mathrm{~cm}^{6} \mathrm{~s}^{-1}$ was reported for methylammonium lead iodide $\left(\mathrm{MAPbI}_{3}\right)$ perovskite thin films. ${ }^{[5]}$ Fortunately, SRH recombination may be engineered away through process sophistication, eliminating the detrimental impact of the responsible defects in the material. For such recombination, the density of defects, their spatial and energetic distribution within the bandgap, as well as capture cross sections for electrons and holes $\left(\sigma_{\mathrm{e}}\right.$ and $\sigma_{\mathrm{h}}$, expressing the probabilities of free electrons or holes being captured in a defect state, respectively) all play a role in the expression for the SRH recombination rate, $U_{\mathrm{SRH}}$, dictating also the dependence of $\tau_{\mathrm{SRH}}$ on $\Delta n$ (Figure 1a). Often, a simplified expression is considered, $\tau_{\mathrm{SRH}}=$ $\left(v_{\mathrm{th}} \sigma \mathrm{N}_{\mathrm{T}}\right)^{-1}$, which is independent of $\Delta n$. This relation represents either the low- or high-injection limit of $\tau_{\mathrm{SRH}}$, and only takes into account the defect density $\mathrm{N}_{\mathrm{T}}$, a single capture cross section $\sigma$, and the thermal velocity $v_{\text {th }}$. In the low-injection limit, $\sigma$ is the capture cross section for the minority carriers; in the high-injection limit $\sigma$ equals $\sigma_{e} \sigma_{h} /\left(\sigma_{e}+\sigma_{h}\right)$. This explains the $S$-shape of $\tau_{\mathrm{SRH}}$, as displayed in Figure 1a. Non-passivated $\mathrm{MAPbI}_{3}$ perovskites have sub-gap trap state densities in the order of $\sim 10^{15}-10^{16} \mathrm{~cm}^{-3}$, compared with $10^{14}-10^{15} \mathrm{~cm}^{-3}$ for others thin film technologies such as CIGS and CdTe. ${ }^{[14,15]}$ We note that the perovskite $\sigma$ values $\left(\sim 10^{-15} \mathrm{~cm}^{2}\right.$, measured by deep level transient spectroscopy, DLTS) are also comparable to that of other wellknown absorbers (CIGS $\sim 10^{-16} \mathrm{~cm}^{2}$, CdTe $\sim 10^{-15}-10^{-17} \mathrm{~cm}^{2}$, GaAs $\left.10^{-13}-10^{-15} \mathrm{~cm}^{2}\right) .{ }^{[16]}$ Overall, we find thus that PSCs have a comparable electronic quality as other well established thin-film photovoltaic absorbers, which can be further improved by passivation schemes. 
Surface recombination is essentially identical to SRH recombination, if only surface defects are taken into account. The surface recombination lifetime $\left(\tau_{\text {surf }}\right)$ inversely scales with surface recombination velocity, $1 / \tau_{\text {surf }}=\left(S_{1}+S_{2}\right) /$ d, with $S_{1,2}$ the surface recombination velocities at the respective surfaces and $d$ the film thickness. Evidently, for low $S$, $\tau_{\text {eff }}$ approaches $\tau_{\text {bulk. }}{ }^{[17]}$ Experimentally, for polycrystalline methylammonium lead iodide $\left(\mathrm{MAPbI}_{3}\right)$ films, $S$ was reported to decrease from $\sim 10^{3}-10^{4} \mathrm{~cm} \mathrm{~s}^{-1}$ to $4.5 \times 10^{2} \mathrm{~cm} \mathrm{~s}^{-1}$ in the presence of methylammonium $\left(\mathrm{MA}^{+}\right)$ rich surfaces, indicating effective surface passivation. ${ }^{[17,18]}$ It is of note that the $S$ of such polycrystalline films is found to be much smaller than that of single-crystal perovskites, which suggests synthesis-specific self-passivation effects. ${ }^{[17]}$ Nevertheless, with the obtained $S$ values, surface recombination remains one of the main limiting mechanism for $\tau_{\text {eff }}$ of such polycrystalline perovskite films, which mandates the search for more effective surface and contact passivation strategies.

\subsection{High Electronic Quality of Perovskites Leads to Efficient Photovoltaics}

\subsubsection{Role of Grain Boundaries on Recombination}

In polycrystalline films, defects such as interstitials and vacancies can be present in the bulk of the grains, at their surface, and especially at their GBs, often making them prime suspects as sources of recombination. Nevertheless, for CZTS, CIGS, and CdTe films, experimental and theoretical studies have also associated benign effects with the presence of GBs. ${ }^{[19,20]}$ This can be explained by the fact that defects and impurities at GBs can induce electrostatic potential barriers, which can cause the spatial separation of photogenerated electrons and holes, ${ }^{[20]}$ decreasing carrierrecombination at GBs. For perovskites, some simulation and experimental studies also report beneficial effects to GBs for charge separation ${ }^{[21,22]}$, whereas many others define GBs as 
recombination centers. ${ }^{[23]}$ Yin et al. proposed that $\mathrm{GBs}_{\text {at }} \mathrm{MAPbI}_{3}$ do not introduce deep gap states. ${ }^{[24]}$ However, the defect level close to the valence band maximum (VBM) may still act as a shallow hole trap. Due to the accumulation of ionic defects at GBs, these regions are positively charged when the trap states are empty and neutral when the trap states are filled with photogenerated electrons. ${ }^{[25]}$ de Quilettas et al. have argued that perovskite GBs show faster nonradiative decay than within the grains by correlating photoluminescence (PL) dynamics with fluorescence microscopy experiments. ${ }^{[15]} \mathrm{A}$ recent study revealed that the grain size heterogeneity and presence of specific crystal facets at the GBs should also be considered when investigating the role of GBs. ${ }^{[26]}$ On device level, numerical simulations indicate that increasing the grain size should result in higher PCEs. ${ }^{[27]}$ These findings have been confirmed experimentally, using perovskite films with grain size varying from the nano-to-micrometer scale, obtained by techniques such as additive engineering, hot casting, and solvent annealing. ${ }^{[28,29]}$ From this, fabrication of thin $(<1 \mu \mathrm{m})$, single-crystal films seems to hold great promise for improved device performance (Figure 1b and 1c). Alternatively, as can be seen from theoretical work shown in Figure 1d, PCEs as high as $24-25 \%$ may be achieved with a grain size of only $10 \mu \mathrm{m}$, provided that GBs and surface defects be eliminated. ${ }^{[27]}$ Along similar lines, theoretically, a $V_{\text {OC }}$ of $\sim 1.27$ $\mathrm{V}$ has been argued to be attainable for $\mathrm{MAPbI}_{3}$ perovskite with grain size as small as $\sim 500 \mathrm{~nm}$, by reducing the trap densities at GBs to values around the order of $10^{9}-10^{10} \mathrm{~cm}^{-3} \cdot{ }^{[30]}$ Millimeterscale grains or single-crystal thin films may thus not be mandatory to approach the practical PCE limits of the PSCs, under the condition that effective surface and GB passivation is implemented. 

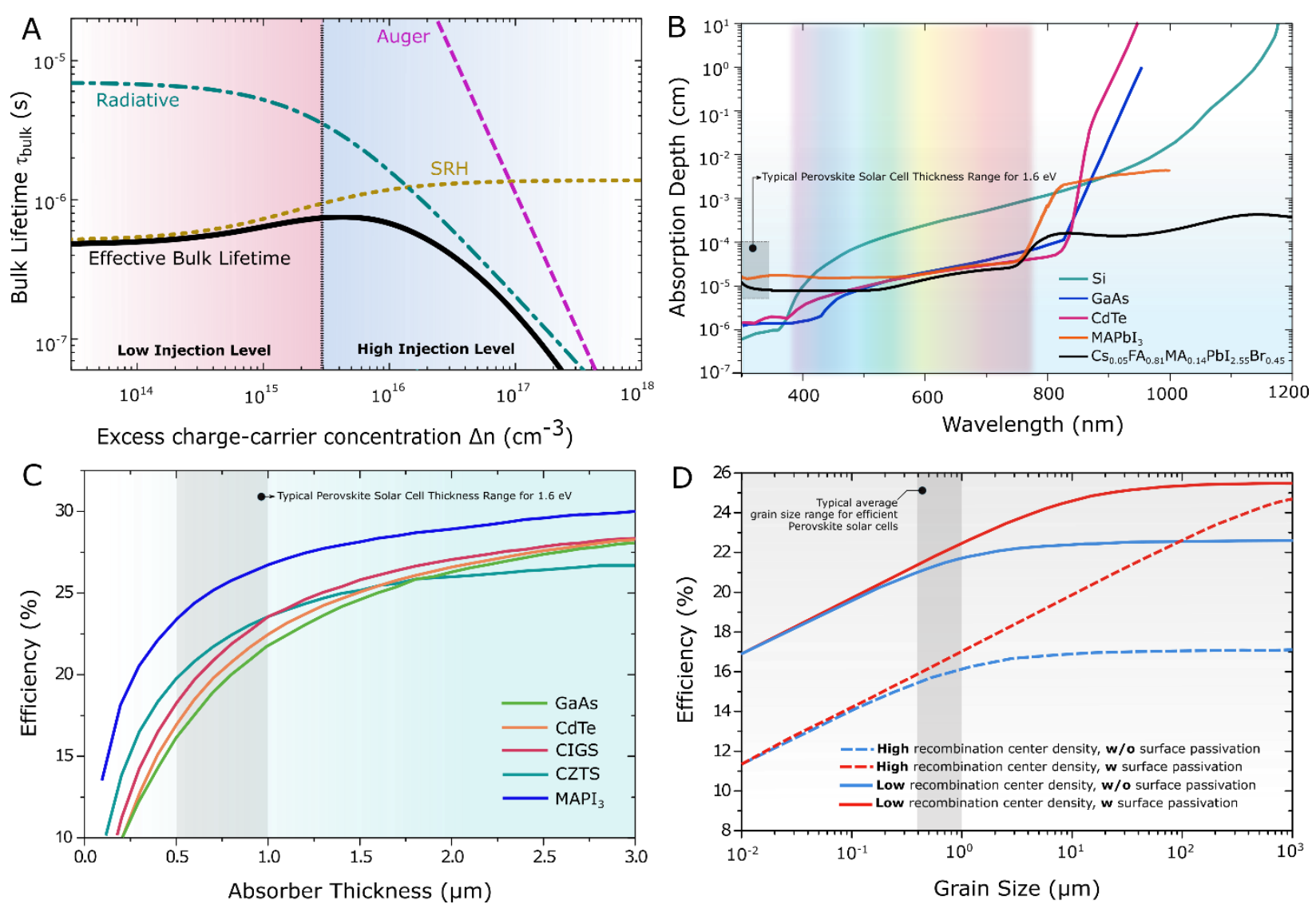

Figure 1. Effective bulk lifetime as a function of $\Delta n$ in perovskites for a $p$-type doping concentration of $p_{0}=3 \times 10^{15} \mathrm{~cm}^{-3}$ (Reproduced with permission ${ }^{[10]}$ ). b) Absorption depth of some state-of-the-art solar cell technologies which is derived from absorbance measurement using $1 / \alpha$ formula (Some data are reproduced from ${ }^{[31]}$ ). c) Calculated maximum PCEs for different thin-film absorber technologies as a function of film thickness (Reproduced with permission ${ }^{[21]}$ ). d) Device efficiency simulation result of PSCs as a function of grain size and surface passivation for the thickness of $500 \mathrm{~nm}$ (Reproduced with permission ${ }^{[27]}$ ).

\subsubsection{Merits of High Electronic Quality of Perovskite Absorbers}

Low voltage losses are characteristic for high-efficiency solar cells. As discussed earlier, nonradiative recombination, which can have multiple causes, results in lower voltages, both at open circuit, as well as actual operating conditions, such as at MPP. Figure 2a summarizes the maximum achieved $\mathrm{V}_{\mathrm{OC}}$ values for a series of different state-of-the-art laboratory solar cells, relative to their respective optical bandgaps and Shockley-Queisser limits. To better compare technologies using absorbers with different bandgaps, $\mathrm{W}_{\mathrm{OC}}$, as defined earlier, is a useful 
parameter. We note that all marked PSCs in Figure 2 correspond to devices featuring some form of contact passivation, to be discussed below. Empirically, the $\mathrm{W}_{\mathrm{OC}}$ value can be correlated with the Urbach energy, $E_{0}$, of the corresponding absorber material; $E_{0}$ expresses the steepness of the absorption edge below the bandgap. Small values of $E_{0}$ point to a sharp absorption edge and a well-ordered microstructure of the material. For state-of-the-art photovoltaic materials, a small $E_{0}$ appears to correlate well with a low $W_{O C},{ }^{[2,32]}$ as can also be seen in Figure 2b. Therefore, this parameter is a useful first indicator of the electronic quality of semiconductors, without requiring sophisticated device fabrication. Using Fourier transform photocurrent spectroscopy (FTPS), the $E_{0}$ value of $\mathrm{MAPbI}_{3}$ was measured to be as low as $13.1 \mathrm{meV},{ }^{[33]}$ which is very close to $\mathrm{GaAs}$ (7.5 $\mathrm{meV}$, both values at room temperature ${ }^{[34]}$. This low $E_{0}$ value is nowadays considered to be one of the key characteristic features of metal halide perovskites. The origin of such a high electronic quality may be speculated to stem from strong coupling between cation $\mathrm{Pb}$ lone-pair $s$ orbitals and anion $p$ orbitals and the large atomic size of constitute cation atoms; ${ }^{[24]}$ the $s$-orbital lone pair represents a pair of valence electrons in the outermost shell of atoms which is not used in any bond between atoms. Overall, we find thus that perovskites intrinsically feature a low energetic disorder, which is necessary criterion for high electronic quality. However, to unlock this intrinsic quality, perovskites must be further improved by passivation of local bulk defects, as discussed below.

The FF of a solar cell is defined as the product of its current and voltage at maximum power output (relative to the product of its short-circuit current, ISC, and $\mathrm{V}_{\mathrm{OC}}$ ). Therefore, the FF is strongly affected by the series and shunt resistance, but also by carrier recombination (at maximum power point conditions). ${ }^{[35]}$ The latter effect is well illustrated by the semi-empirical expression given in Eqn (3), showing the dependency of FF on the $\mathrm{V}_{\text {OC. }}{ }^{[35,36]}$ 
$F F=\frac{v_{m}}{v_{m}+1} \frac{v_{o c}-\ln \left(v_{m}+1\right)}{v_{o c}\left(1-e^{-v_{o c}}\right)}$

In this, $v_{\mathrm{oc}}=V_{o c} / n k_{B} T, v_{\mathrm{m}}=v_{\mathrm{oc}}-\ln \left(v_{\mathrm{oc}}+1-\ln v_{\mathrm{oc}}\right), k_{B}$ is the Boltzmann constant, $T$ is the temperature, $q$ is elemental charge, and $n$ is the diode ideality factor.

Figure 2c plots the dependency of the FF on WoC for PSCs with different $E_{g}$ and compares these values with those for some state-of-the-art laboratory cells (as of Jan. 2019). Empirically, this figure clearly demonstrates the universal trend how low WOC values enable high FF values, independently from the specific solar cell technology. For a given $\mathrm{W}_{\text {OC }}$, an even higher FF may still be possible by reducing the resistive losses of the contact stacks, such as the contact resistance (see arrow in Figure 2d). Specifically, this figure reveals that PSCs have a high FF potential thanks to their small Wocs. However, the reported experimental FF values do not yet reach this potential. This contrasts with the case of other, more established crystalline absorber technologies. In particular, Figure 2d suggests that the currently employed (passivating) contact stacks in PSCs may result in relatively large resistive losses. Combined, all panels in Figure $\mathbf{2}$ brings forward a strict hierarchy that needs to be obeyed, if one aims to develop a new high-performance solar cell technology: First of all, the employed absorber material should feature a low $E_{0}$ energy; if not, it will be impossible to reach high operating voltages and FF values, no matter how sophisticated subsequent cell processing. If the low $E_{0}$ energy condition is fulfilled, implementation of bulk defect passivating strategies, followed by the integration of low-resistance, passivating contacts are then next steps required to unlock the full potential of an absorber material for photovoltaics. 

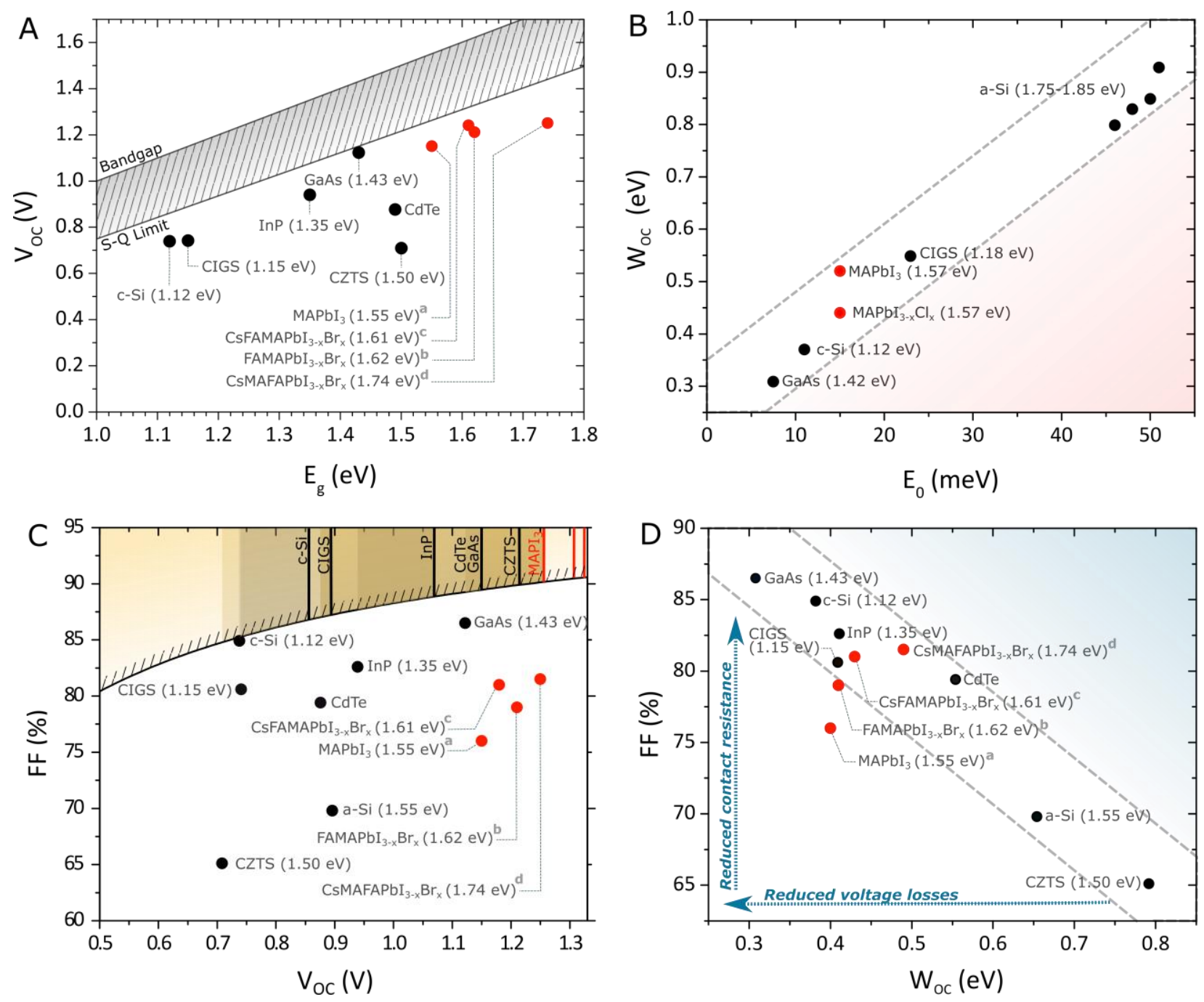

Figure 2. a) The $V_{O C}$ values for the champion laboratory cells. The shaded gray area shows the difference between bandgap and Shockley-Queisser limits for given bandgap value. ${ }^{[37]} \mathrm{b}$ ) The correlation between $E_{0}$ and $\mathrm{W}_{\mathrm{OC}}$ for typical absorber materials. The values in the parenthesis are showing the $E_{g}$ of the selected absorbers. (Reproduced with permission ${ }^{[2]}$ ). b) The dependency of FF on c) $V_{O C}$ and d) $\mathrm{W}_{O C}$ for the state-of-the-art PV devices. FF values were taken from the literature for different absorber technologies ${ }^{[38]}$. For panel c, the thick vertical solid lines shows the Shockley-Queisser limits for the given bandgap. For PSCs, the FF values were taken from $a={ }^{[39]}, b={ }^{[40]}, c={ }^{[41]}, d={ }^{[42]}$. All reported PSCs to have contact passivation. Shaded areas represent physically inaccessible parameter space. The dashed lines are only guide to the eye

\section{Passivation Routes in Perovskite Solar Cells}

\subsection{Bulk Defect Passivation}


Thermodynamically, perovskite crystals have low defect-formation energies. ${ }^{[43]}$ Interstitial (e.g., $\left.P b_{i}\right)$ and substitutional defects $\left(e . g ., I_{P b}, I_{M A}, P b_{I}\right)$ form deep-level defects within the perovskite crystal, resulting in non-radiative recombination losses ${ }^{[43]}$ Recent theoretical studies proposed that positively charged iodide vacancies $\left(V_{\mathrm{I}}^{+}\right)$are the dominant defect species in $\mathrm{MAPbI}_{3}$ perovskites, together with $\mathrm{Pb}^{2+}\left(V_{P b^{2}}{ }^{2-}\right)$ and $M A^{+}\left(V_{M A^{-}}\right)$vacancies. ${ }^{[44]}$ Such vacancies may form shallow levels near the band edges, acting as unintentional doping sites. Although $\mathrm{MAPbI}_{3}$ is considered to be ionic, showing very weak covalency, first-principles calculations revealed strong covalency of both the $\mathrm{Pb}^{2+}$ cation and $\mathrm{MA}^{+}$anion in $\mathrm{MAPbI}_{3} \cdot{ }^{[45]}$ Accordingly, the formation of $\mathrm{Pb}_{2}{ }^{+}$dimers and $I_{3}{ }^{-}$trimers in the $\mathrm{MAPbI}_{3}$ crystal due to such strong covalency gives rise to deep charge-state transition levels within the bandgap. ${ }^{[45]}$ Such defects create a gap level occupied by electrons, which could take thus the role as effective recombination centers. ${ }^{[46]}$ On the other hand, low formation-energy defects such as $M A_{i}, V_{P b}, M A_{P b}, I_{i}, V_{I}$, and $V_{M A}$, have shallow levels at less than $0.05 \mathrm{eV}$ above (below) VBM (conduction band minimum, CBM), making them inactive for recombination..$^{[47]}$

$\mathrm{MAPbI}_{3}$ is one of the most well-known perovskite absorbers. However, a notable issue with this material is that its $\mathrm{MA}^{+}$ions tend to leave from the perovskite crystal upon heat and light exposure ${ }^{[48]}$ Therefore, mitigation of $M A^{+}$cations by alternative cations emerged as an important direction in research. Practically, the monovalent cations which have Goldschmidt tolerance factors between 0.8 and 1 can enter the lattice and form photoactive phases. ${ }^{[4]}$ Cations with smaller atomic radius than $\mathrm{MA}^{+}$such as $\mathrm{Rb}^{+}, \mathrm{K}^{+}, \mathrm{Na}^{+}$, and $\mathrm{Li}^{+}$are also alternatives for $\mathrm{MA}^{+}$replacement. However, ions smaller than $C s^{+}$may accumulate at the GBs or be located at lattice defects instead of replacing the organic or inorganic cations. In this fashion, $K^{+}$incorporation into the triple-cation CsFAMAPbI $\mathrm{B}_{\mathrm{x}} \mathrm{B}_{\mathrm{x}}$ structure increased the grains size up to $\sim 1 \mu \mathrm{m}$, double the size of its $K$-free 
counterparts. ${ }^{[49]}$ The increased grain size of the perovskite absorber provides some benefits such as decreased trap density, increased PL lifetime and reduced hysteresis. Besides, these improvements resulted in a $\mathrm{V}_{\mathrm{OC}}$ enhancement on device level: $1.132 \mathrm{~V}$ has been reported for KCsFAMAPbI ${ }_{x} B_{3-x}$ devices, to be compared with $1.085 \mathrm{~V}$ and $1.097 \mathrm{~V}$ for $\mathrm{FAMAPbI}_{\mathrm{x}} \mathrm{B}_{3-\mathrm{x}}$ and CsFAMAPbI ${ }_{x} B_{3-x}$ devices, respectively. On the other hand, Dae-Yong et al. reported that $K^{+}$ incorporates into the perovskite lattice as a Frenkel defect due to the optimal cation/anion radius ratio. ${ }^{[50]}$ The $K^{+}$ion fits well into the octahedral interstitial site and thus prevents ion migration. According to this hypothesis, the authors attributed the origin of the hysteresis to Frenkel defects rather than migration of $V_{I}$, as Frenkel defects are induced by electron accumulation at the cathode, and $\mathrm{K}^{+}$incorporation minimizes this type of defect formation. Abdi-Jalebi et al. also claimed that $K^{+}$atoms are decorating the surfaces and grain boundaries of the perovskite layer. ${ }^{[51]}$ This process immobilizes the excess of halide and vacancies by forming inert K-based complexes at the grain boundaries and surfaces. ${ }^{[52]}$ All these improvements can be identified as a self-passivation effect via $K^{+}$incorporation into the perovskite structure.

$\mathrm{MAPbI}_{3}$ can be doped with metal ions with higher valency than $P b^{2+}$. For example, Wang et al. showed that at low $A l^{3+}$ doping concentrations the density of crystal defects decreased, which was attributed to reduced microstrain in the lattice. ${ }^{[33]}$ Furthermore, $\mathrm{Al}^{3+}$ doping showed a reduction in $E_{0}$ from 13.09 to $12.64 \mathrm{meV}$, which is indicative for reduced disorder in the lattice and suggests improved electronic quality of the perovskite films. Similarly, doping with monovalent cation halides such as $\mathrm{Cu}^{+}$, $\mathrm{Na}^{+}$, and $\mathrm{Ag}^{+}$with comparable ionic radii to $\mathrm{Pb}^{2+}$ was proposed to passivate the surface or GBs of MAPbI 3 perovskites. ${ }^{[53]}$ Moreover, doping of the $\mathrm{MAPbI}_{3}$ by $\mathrm{Pb}^{2+}$ substitution with $\mathrm{Sn}^{2+}, \mathrm{Sr}^{2+}, \mathrm{Cd}^{2+}$, and $\mathrm{Ca}^{2+}$ was found to affect both the crystalline phase and the band-gap due to the different ionic interactions with iodine and divalent cations. ${ }^{[54]}$ Incorporation of $C d^{2+}$ to the perovskite lattice, which is 
isovalent to $P b^{2+}$ but has a smaller ionic radius, was found by Saidaminov et al. to increase the stability of the devices (maintaining $>90 \%$ of their initial PCE after 30 days) by releasing the lattice strain and increasing the formation energy of vacancies. ${ }^{[55]}$ Recently $\mathrm{Ni}^{2+}$ ions were found to passivate the $\mathrm{PbI}_{3}{ }^{-}$ anti-site defects and enhance the PL lifetime from 285 to $732 \mathrm{~ns}$ by increasing the crystal order and grain size ${ }^{[56]}$ For wide $E_{g}$ perovskites, engineering the cation composition can help to achieve low $\mathrm{W}_{\mathrm{OC}}$ values, which is critical to achieve high-performance perovskite-based tandem solar cells. Owing to its strong dipole moment, incorporation of the $\mathrm{MA}^{+}$cation to the mixed cation-halide wide bandgap perovskites reduces the formation of deep trap defects as well as healing the defects. Such treatment enables $\mathrm{V}_{\mathrm{OC}}$ as high as $1.25 \mathrm{~V}$ for $E_{g}=1.74 \mathrm{eV} .^{[42]}$

Interestingly, perovskite defects were proven to be passivated also through light exposure. Indeed Tsai et al. and Mosconi et al. experimentally and theoretically found that self-healing of bulk defects may occur, induced by applyng a light bias to the material. Moreover, this photo-induced passivation phenomenon was found by Tsai et al. more pronounced for mixed cation perovskites, and found to be an important factor to improve devices lifetime. ${ }^{[57]}$

Overall, these results further support the consensus that the perovskite crystal is susceptible to defect formation, and either reducing the defect formation or healing such defects are successful approaches to achieve higher $V_{O C}$ and enhanced operational stability. 


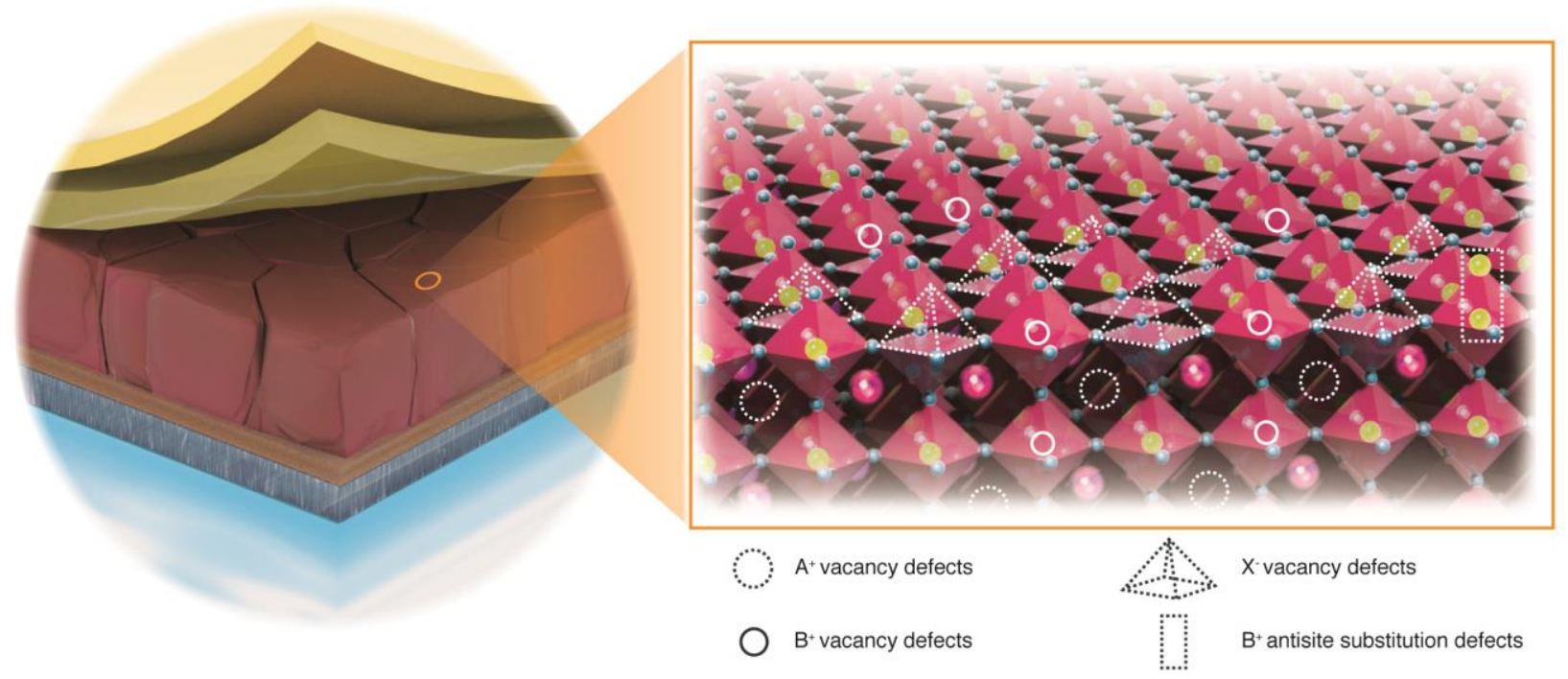

Figure 3. Schematic illustration of typical PSCs and detailed view of possible surface defects on perovskite crystals, e.g., interstitials, substitutional and vacancies.

\subsection{Surface and Grain Boundary Passivation}

In practice, independently from the deposition technique, surfaces and GBs of perovskites accommodate several defects such as cation vacancies and anti-site substitutional defects, as depicted in Figure 3. On device level, the electron-transport and hole-transport layers (ETL and HTL) cover the opposite perovskite surfaces; under actual operating conditions, the photogenerated charges should be transferred to these respective interfaces and subsequently through the respective contact stacks with as little as possible resistance and recombination. However, local PL analysis revealed that these interfaces may act as undesired recombination sites which unfavorably affects the voltages and the charge-transfer processes on device level. ${ }^{[58,59]}$ To overcome surface recombination, tailored passivation schemes should be implemented at the interfaces. This can be done typically by i) chemical passivation, and ii) field-effect passivation, or iii) a combination of both. Figure 4 sketches the three possible passivation mechanisms. With chemical surface passivation, the density of the defects is decreased, leading to reduced 
recombination rates. With field-effect passivation, free charges (either electrons or holes) are repelled from the interface, decreasing the probability of charge trapping at defect sites. In the ideal case, a combination of bulk and surface passivation, without inducing resistive losses, should give the best performance for PSCs. In the following sections, we discuss successful surface and GB passivation schemes, considering these main approaches.
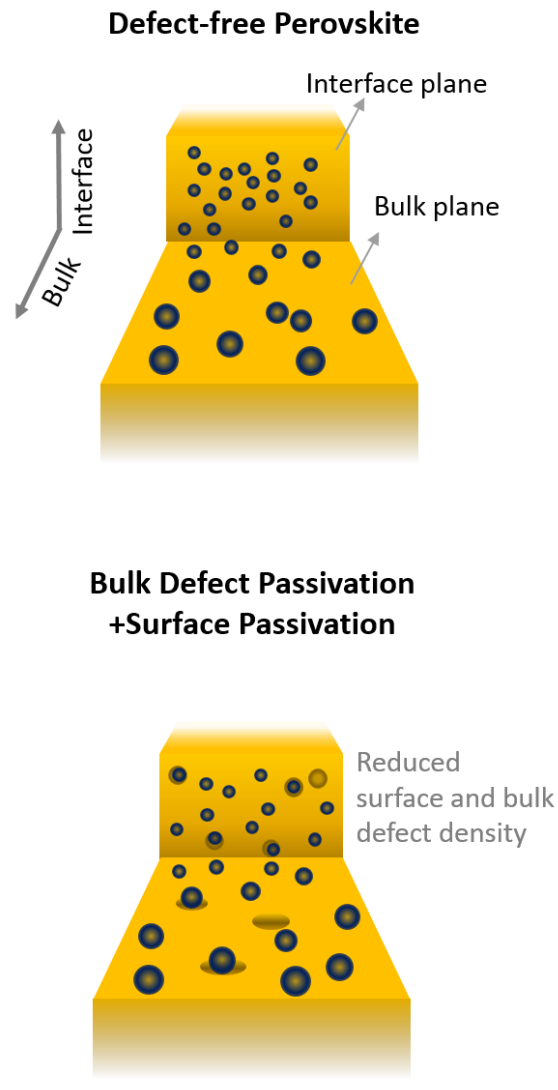

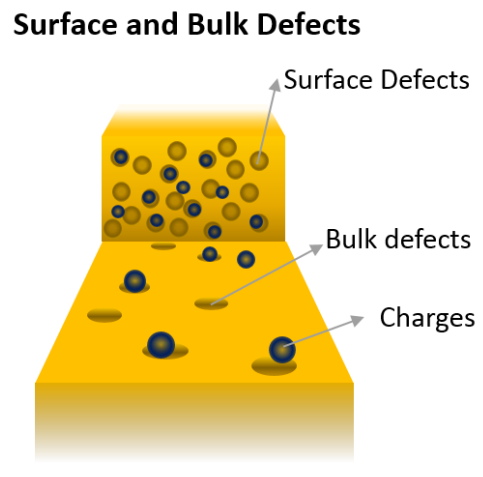

Field-effect Passivation

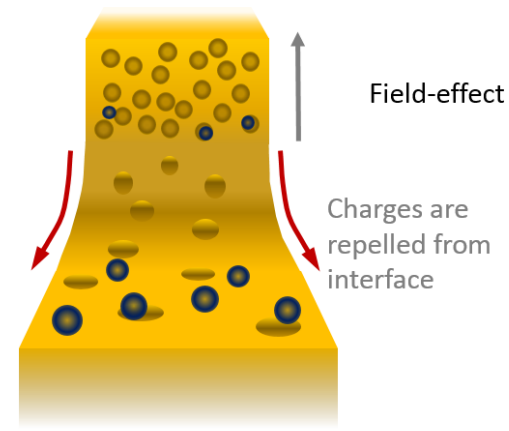

Bulk Defect Passivation

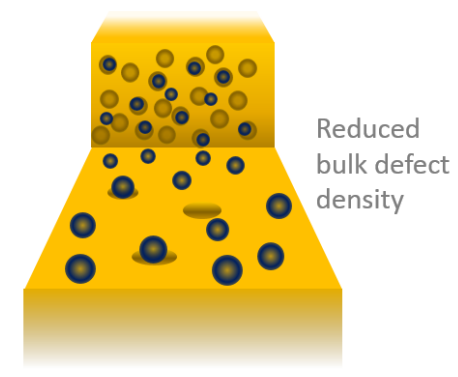

Bulk Defect Passivation +Surface Passivation +Field-effect Passivation

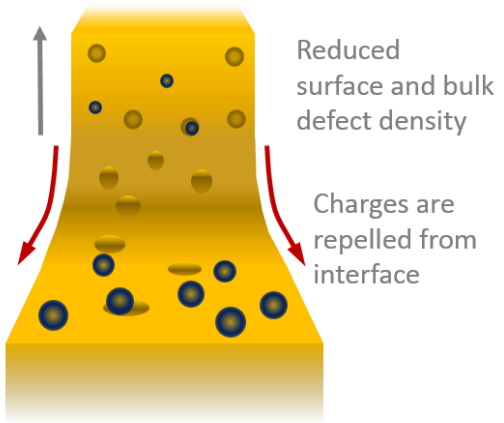

Figure 4. Sketches for the different passivation mechanisms of perovskites. Two different planes represent the bulk and interfaces. Blue spheres represent the charges (electrons or holes) whereas pits are showing the traps states. With bulk and surface passivation, $N_{T}$ can be decreased whereas with field-effect passivation charges can be expelled from the interfaces. These two mechanisms may work together as well.

\subsubsection{Non-stoichiometry}

Ideally, stoichiometric and defect-free perovskite crystals should not have any excess atoms in the structure. For any kind of inorganic material, non-stoichiometric atomic ratios may result in phase 
segregation in the bulk or at the surfaces during the film formation process. In PSCs, this can sometines be exploited as a "self-passivation" effect. In this regard, a controlled excess of lead iodide $\left(\mathrm{PbI}_{2}\right)$ in the perovskite layer has been argued to form a shell around the individual perovskite crystals in the films, improving device performance (Figure 5a) ${ }^{[60]}$ Reduced carrier recombination at the GBs as well at the interfaces the perovskite shares with the ETL and HTL is likely the main reason for such improved performance. ${ }^{[61]}$ However, an excess in the concentration of $\mathrm{PbI}_{2}$ can easily generate potential barriers at the extraction layers, due to the large bandgap of $\mathrm{PbI}_{2}$ (Figure 5b and 5c). ${ }^{[29,62,63]}$ Such potential barriers affect the charge transport properties and may induce carrier accumulation at the interfaces. On the other hand, a too low concentration of $\mathrm{PbI}_{2}$ may be insufficient to passivate the GBs and generate unwanted secondary effects such as ion migration and hysteresis, which severely affect the stability of devices. ${ }^{[64]}$ However, by careful optimization of the excess amount of $\mathrm{PbI}_{2}$, a certified 20.9\% PCE was achieved on tin oxide $\left(\mathrm{SnO}_{2}\right)$ ETL which is showing the potential of the technique (Table 1).

Similarly, an excess of methylammonium iodide (MAI) can passivate GBs. ${ }^{[65]}$ This treatment was proved to increase the $\mathrm{V}_{\text {OC }}$ from 1.029 to $1.118 \mathrm{~V}$ and $\mathrm{FF}$ from 68.3 to $75.5 \%$, resulting in a PCE increase from 16.8 to $19.8 \%$. In this case, a part of the MAI segregates to the GBs during film formation. Moreover, for defect passivation, intergranular MAI forms a conductive and continuous ionic pathway through the GBs. Ultra-thin MAI layers can be used for surface modification as well, ${ }^{[66]}$ optimizing the band alignment between HTL and perovskite layers. With an optimized 4 nm MAI layer on perovskite, the stabilized PCE was reported to be increased from 14.5 to $17.2 \% .^{[66]}$

Along similar lines, formamidinium bromide $(\mathrm{FABr})$ has been used to passivate the surface of mixed-cation mixed-halide perovskites such as $\left(\mathrm{FAPbI}_{3}\right)_{0.85}\left(\mathrm{MAPbBr}_{3}\right)_{0.15}$ (together with an 
excess of $\mathrm{PbI}_{2}$ as well). ${ }^{[67]}$ This treatment forms the wider $E_{g}(1.62 \mathrm{eV}) \mathrm{FAPbBr}_{3-\mathrm{x}} \mathrm{I}_{\mathrm{x}}$ structure at the perovskite/HTL interface, effectively preventing carrier recombination. With this method, the PCE increased from 18.7 to $20.5 \%$, and the $\mathrm{V}_{\text {oc }}$ increased from 1.10 to $1.16 \mathrm{~V}$.

Overall, these studies suggest that other alkyl-ammonium halides might also useful to passivate the defects on the surface of the perovskite crystals. However, segregation of non-perovskite phases may introduce recombination centers; therefore, compositional adjustments should be performed with care.

\subsubsection{Additive Engineering}

Extrinsic additives, such as polymers, fullerene derivatives, inorganic acids, solvents, ionic liquids, and nanoparticles are currently being used to tailor the morphology of the perovskites by altering their crystal-growth dynamics. ${ }^{[68]}$ Such additives have been found to passivate defects, effectively enhancing the $\mathrm{V}_{\mathrm{OC}}$ of devices. As an example, alkylphosphonic acid $\omega$ ammonium cations have been used to cap $\mathrm{MAPbI}_{3}$ crystal surfaces, resulting in the crosslinking of individual perovskite grains. ${ }^{[69]}$ Such crosslinking is provided through strong H-bonding of the $-\mathrm{PO}(\mathrm{OH})_{2}$ and $-\mathrm{NH}_{3}{ }^{+}$terminal groups to the perovskite surface. Due to efficient charge transport through such well-interconnected perovskite networks and the perovskite/ $\mathrm{TiO}_{2}$ interface, a PCE increment from 8.8 to $16.7 \%$ was reported, along with improved device stability (Table 1). Similarly, tertiary amine hexamethylenetetramine $\left[\left(\mathrm{CH}_{2}\right)_{6} \mathrm{~N}_{4}, \mathrm{HMTA}\right]$ was used as an additive to coordinate $\mathrm{Pb}^{+2}$ ions in $\mathrm{MAPbI}_{3}$, yielding vertically aligned crystals and increased adhesion between perovskite and zinc oxide $(\mathrm{ZnO})$ contacts. ${ }^{[70]}$ Thiocyanates are also commonly used as additives. As an example, adding lead thiocyanate $\left[\mathrm{Pb}(\mathrm{SCN})_{2}\right]$ to the perovskite precursor or using it as an interlayer improved all the photovoltaic parameters and reduced hysteresis by significantly increasing the crystallite size and passivating the GBs. ${ }^{[71]}$ Interestingly, 
$S C N^{-}$ions are not found to be incorporated into the perovskite structure. Potentially, when $M A^{+}$cations react with $\mathrm{SCN}^{-}$anions, $\mathrm{HSCN}$ and $\mathrm{CH}_{3} \mathrm{NH}_{2}$ gases are formed during perovskite film growth due to the limited stability of the $\mathrm{CH}_{3} \mathrm{NH}_{3} \cdot \mathrm{SCN}$ adduct. ${ }^{[72]}$ Then, the separation of the HSCN and $\mathrm{CH}_{3} \mathrm{NH}_{2}$ gases induces $\mathrm{PbI}_{2}$-rich phases at the GBs. In turn, this excess of $\mathrm{PbI}_{2}$ provides GB passivation, as already described. Such passivation, combined with a remarkable increment of the grain size, was found to improve the FF and $V_{O C}$ of devices significantly. However, further increasing the excess amount of $\mathrm{PbI}_{2}$ causes performance losses, as also already discussed in the previous section. For this reason, adequate additive ratios of $\mathrm{Pb}(\mathrm{SCN})_{2}$ should be considered for specific perovskite compositions. For instance, a 20.1\% PCE for $\mathrm{MA}_{0.7} \mathrm{FA}_{0.3} \mathrm{PbI}_{3}$ with $3 \% \mathrm{~Pb}(\mathrm{SCN})_{2}$ and a $17.18 \% \mathrm{PCE}$ for the wider bandgap $\mathrm{FA}_{0.8} \mathrm{Cs}_{0.2} \mathrm{~Pb}\left(\mathrm{I}_{0.7} \mathrm{Br}_{0.3}\right)_{3}\left(\mathrm{E}_{\mathrm{g}}=1.75\right.$ $\mathrm{eV})$ with $1 \% \mathrm{~Pb}(\mathrm{SCN})_{2}$ additives were reported, respectively. ${ }^{[73]}$ Foreign additives are far from being limited to these examples, suggesting that additive engineering may become one of the key approaches to enhance the performance of PSCs.

\subsubsection{Fullerene and Graphene-Based Capping}

Fullerene $\left(\mathrm{C}_{60}\right)$ and its derivatives (e.g., $\left.\mathrm{PCBM}, \mathrm{PC}_{70} \mathrm{BM}\right)$ are widely used ETLs in PSCs due to their high mobility, efficient electron-extraction, and hole-blocking properties. Notably, PCBM can also act as a passivation molecule for perovskites by accepting an electron from negatively charged $\mathrm{PbI}_{3}{ }^{-}$anti-site defects or under-coordinated halide ions (Figure 5e) ${ }^{[39]}$ Indeed, spincoating a thin PCBM layer on the perovskite layer leads to a notable PCE enhancement, eliminating the hysteresis as well. ${ }^{[74,75]}$ Blending PCBM molecules into the perovskite precursor can lead to homogeneously distributed PCBM within the GB network of the perovskite. ${ }^{[76]}$ Again, this passivates the $\mathrm{PbI}_{3}{ }^{-}$anti-site defects at GBs. Density functional theory (DFT) calculations suggest that bonding of $\mathrm{PCBM}$ to $\mathrm{PbI}_{3}{ }^{-}$anti-site defects is thermodynamically favorable (Figure 
5d) ${ }^{[76]}$ Such bonding promotes carrier extraction at the grain boundaries via continuous pathways, leading to improved PCEs and reduced hysteresis. On the other hand, fullerene passivation of $V_{I}$ defects creates iodo radicals. This generates iodine that can easily sublime, causing new $V_{I}$ defects, ${ }^{[77]}$ making this approach less desirable. Nevertheless, fullerene passivation is commonly used to prevent hysteresis in PSCs.
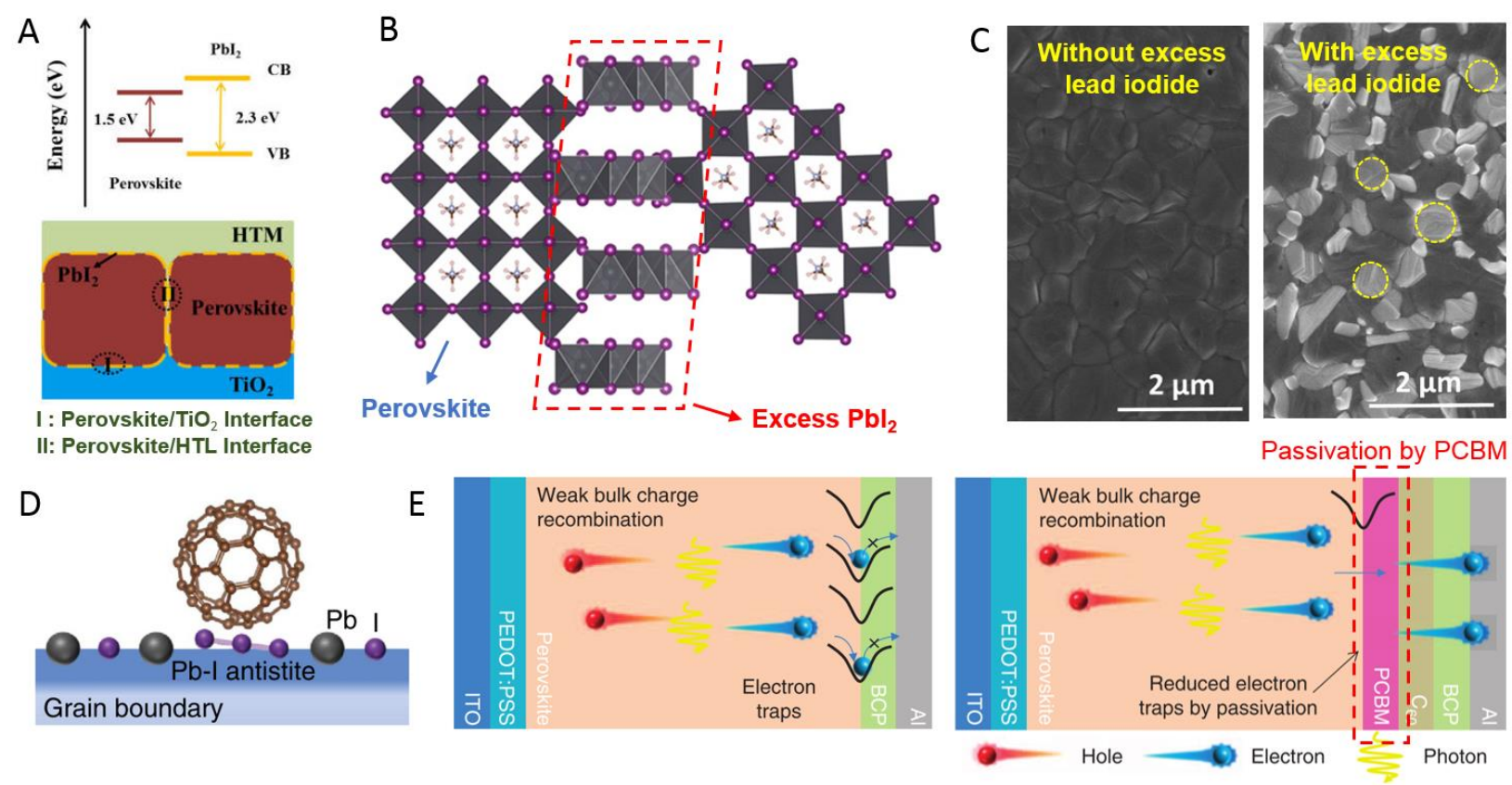

Figure 5. a) Schematic illustration of the excess $\mathrm{PbI}_{2}$ at the perovskite/TiO ${ }_{2}$ and perovskite/HTL interface (Reproduced with permission ${ }^{[60]}$ ). b) GB with a large surplus of $\mathrm{PbI}_{2}$ (Reproduced with permission ${ }^{[62]}$ ). c) SEM surface morphology of the perovskite layer with and without excess $\mathrm{PbI}_{2}$ layer (Reproduced with permission $\left.{ }^{[64]}\right)$. d) A schematic of PCBM passivation of Pb-I anti-site defective GB (Reproduced with permission ${ }^{[76]}$ ). e) Illustration of the elimination of surface recombination by passivating the trap states (Reproduced with permission ${ }^{[74]}$ ).

\subsubsection{Lewis Acid-Base Adduct Surface Modification}

Electron-rich and electron-poor chemicals (i.e., weak Lewis acids and bases) can create strong chemical bonds. Similarly, halogenated organic compounds and halide anions create a strong interaction via halogen bonding. Therefore, the Lewis acid/base adduct approach can be used to passivate halide defects present in perovskites such as undercoordinated halide ions at the 
perovskite/HTL interface, which act as traps for the hole. To resolve this issue, halogenated organic compounds such as iodopentafluorobenzene (IPFB) can be used to passivate the perovskite/spiro-OMeTAD interface. Using electronegative fluorine atoms, IPFB withdraws electrons from the iodine, bonded to the aromatic ring. This leaves a partially positive charge on the halogen. ${ }^{[78]}$ In this way, IPFB strongly interacts by supramolecular halogen bonding with the undercoordinated halide ions (Figure 6a) ${ }^{[79]}$ As a consequence of IPFB passivation, the FF of the devices is dramatically improved whereas the $\mathrm{J}_{\mathrm{SC}}$ and $\mathrm{V}_{\mathrm{OC}}$ remained unchanged.

Similarly, thiophene and pyridine can passivate under-coordinated $\mathrm{Pb}^{+2}$ atoms on the surface of $\mathrm{MAPbI}_{3-\mathrm{x}} \mathrm{Cl}_{\mathrm{x}}$ perovskite, significantly reducing defect-assisted recombination. ${ }^{[80]}$. Along these lines, electron-rich sulfur $\left(\delta^{-}\right)$atoms of hexylthiophenes also passivate the positively charged surface defects $\left(\delta^{+}\right) .{ }^{[81]}$ Alternatively, indacenodithiophene, end-capped with 1.1dicyanomethylene-3-indanone (IDIC) may be used, through interaction between the undercoordinated $\mathrm{Pb}^{+2}$ sites and the cyano $(\mathrm{C} \equiv \mathrm{N})$ and carbonyl $(\mathrm{C}=\mathrm{O})$ groups of a $\pi$-conjugated Lewis base. ${ }^{[82]}$ Here, IDIC efficiently extracts electrons from the perovskite due to its $n$-type semiconducting properties, replacing the standard PCBM layer. Such passivation was observed to increase the $\mathrm{V}_{\mathrm{OC}}$ of the devices from 1.03 to $1.11 \mathrm{~V}$.

Lewis acids/bases passivate either positively or negatively charged defects. However, both types of defects may simultaneously be present on perovskite surfaces. In this context, zwitterion molecules (quaternary ammonium halides) can be a choice as passivants, since the ammonium and the halide ions are positively and negatively charged, respectively (Figure 6b). ${ }^{[83]}$ With choline chloride passivation, the PCE of PSCs with different perovskite compositions was increased, compared with the devices with PCBM passivation. This modification resulted in one of the highest PCE (21\%) for $p-i-n$ PSCs. ${ }^{[39]}$ 
Surface treatments by strong electron acceptors such as 2,3,5,6-Tetrafluoro-7,7,8,8tetracyanoquinodimethane (F4TCNQ) can also be used as a p-type surface dopant, where electrons diffuse from the perovskite to the lowest unoccupied molecular orbital (LUMO) of F4TCNQ. ${ }^{[84]}$ Practically, this process results in $p$-type doping of the perovskite surface. The induced field-effect passivation at the interface blocks electrons from diffusing to the HTL. Additionally, F4TCNQ interacts with iodine ions in the perovskite through halogen bonding, in this way, F4TCNQ yields field-effect and chemical passivation simultaneously. Alternatively, benzenethiol, which is an organosulfur compound forming $\mathrm{Pb}-\mathrm{S}$ coordination bonds, also changes the interfacial dipole moment and band alignment, resulting in a more facile charge transfer. ${ }^{[85]}$

A proper selection of passivating molecules can also aid in improved moisture stability, along with enhanced PCEs. Among these, benzylamine modification of formamidinium lead iodide $\left(\mathrm{FAPbI}_{3}\right)$ films is an example. ${ }^{[86,87]}$ In this case, the amino groups help to anchor these molecules to the $\mathrm{Pb}$ I framework with two possible scenarios: i) through coordination with the $P b^{+2}$ ions or ii) forming $H$ bonding with the iodide ions. Whereas the $\pi$-conjugation structure favors an enhanced charge transport, the hydrophobic nature of the benzene rings aids in moisture stability of the perovskite layer. Integrated into devices, this treatment improved both $\mathrm{V}_{\mathrm{OC}}$ and $\mathrm{J}_{\mathrm{SC}}$, resulting in an PCE increase from 14.2 to $17.2 \%$ and enhanced stability of the devices for more than four months in moist air. With a similar approach, PFN-2TNDI molecules (amino-functionalized copolymer semiconductor) were used for passivation purposes. ${ }^{[88]}$ Here, the nitrogen atom in the alkylamine side of PFN-2TNDI provides the electron-rich functional group. This neutralizes the excess of positive charges which are induced by undercoordinated metal atom on the surface of the perovskite crystal by donating lone pair electrons to $\mathrm{Pb}^{+2}$ atoms. 
Similarly, graphene and graphene oxide can be used to enhance electron extraction from the perovskite absorber. Graphene quantum dots (GQD) have already been used for GB passivation, forming a $\mathrm{H}$ bond between $\mathrm{MAPbI}_{3}$ and $\mathrm{C}_{24} \mathrm{H}_{12}$. With careful optimization of the $\mathrm{GQD} /$ perovskite blend, the GB recombination rate was decreased with the help of the conductive nature of GQDs, and the PCE of the devices was improved from 16.29 to $17.62 \% .{ }^{[89]}$ Functionalized graphene oxide was also found to successfully passivate perovskite surfaces (Figure $6 \mathbf{6 c}$ ) ${ }^{[90]}$ Functional groups of graphene flakes (4-Fluorophenyl) may interact with under-coordinated $\mathrm{Pb}^{+2}$ ions, whereas graphene oxide enhances the extraction of holes as supported by the enhancement of the $V_{O C}$ from 1.03 to $1.11 \mathrm{~V}$.

Overall, all these techniques have proved to yield remarkable increments in PCE, showing the compelling side of the Lewis acid-base adduct method to passivate the surface defects of the perovskite crystals. Within this approach, alternative chemicals, which can co-passivate the different charged defects, may further increase the $V_{O C}$, close to its practical limit.

\subsubsection{Ultrathin Dielectric Oxide Layer Capping}

Surface defects of $c$-Si solar cells are often passivated by ultrathin dielectric materials such as silicon oxide $\left(\mathrm{SiO}_{\mathrm{x}}\right)$, silicon nitride $\left(\mathrm{SiN}_{\mathrm{x}}\right)$, aluminum oxide $\left(\mathrm{Al}_{2} \mathrm{O}_{3}\right) \cdot{ }^{[13]}$ These layers provide either chemical passivation, by removing the sub-band gap energy states associated with Si dangling bonds at the surface, or field-effect passivation (often based on fixed-charge densities embedded in the dielectric layer, close to the $c$-Si surface), which screens the defects either from electrons or holes. Taking inspiration from this, ultrathin dielectric materials can also be used to passivate perovskite surfaces. Atomic layer deposition (ALD) of ultrathin $(\sim 1 \mathrm{~nm}) \mathrm{Al}_{2} \mathrm{O}_{3}$ has been reported for chemical passivation of surface defects of perovskites as well as impeding moisture ingress (Figure 6d). ${ }^{[1]}$ With $\mathrm{Al}_{2} \mathrm{O}_{3}$ 
passivation, the $\mathrm{V}_{\mathrm{OC}}$ of devices increased by $50 \mathrm{mV}$, and their PCE increased from $15.1 \%$ to $18 \%$ (Table 1). With a similar approach, other metal oxides, and possibly nitrides and carbides, may be used for passivation as well. To date, only a few studies reported metal-oxide passivation by ALD since this technique often requires water cycles in the growth process which can be detrimental for the structural stability of the perovskites. ${ }^{[92]}$ Sometimes, ALD precursors also can degrade the perovskite absorber. To avoid such degradation, deposition parameters such as employed precursors, water cycles and temperature should be carefully optimized. Alternatively, other non-destructive techniques should be developed for ultrathin conformal coatings.

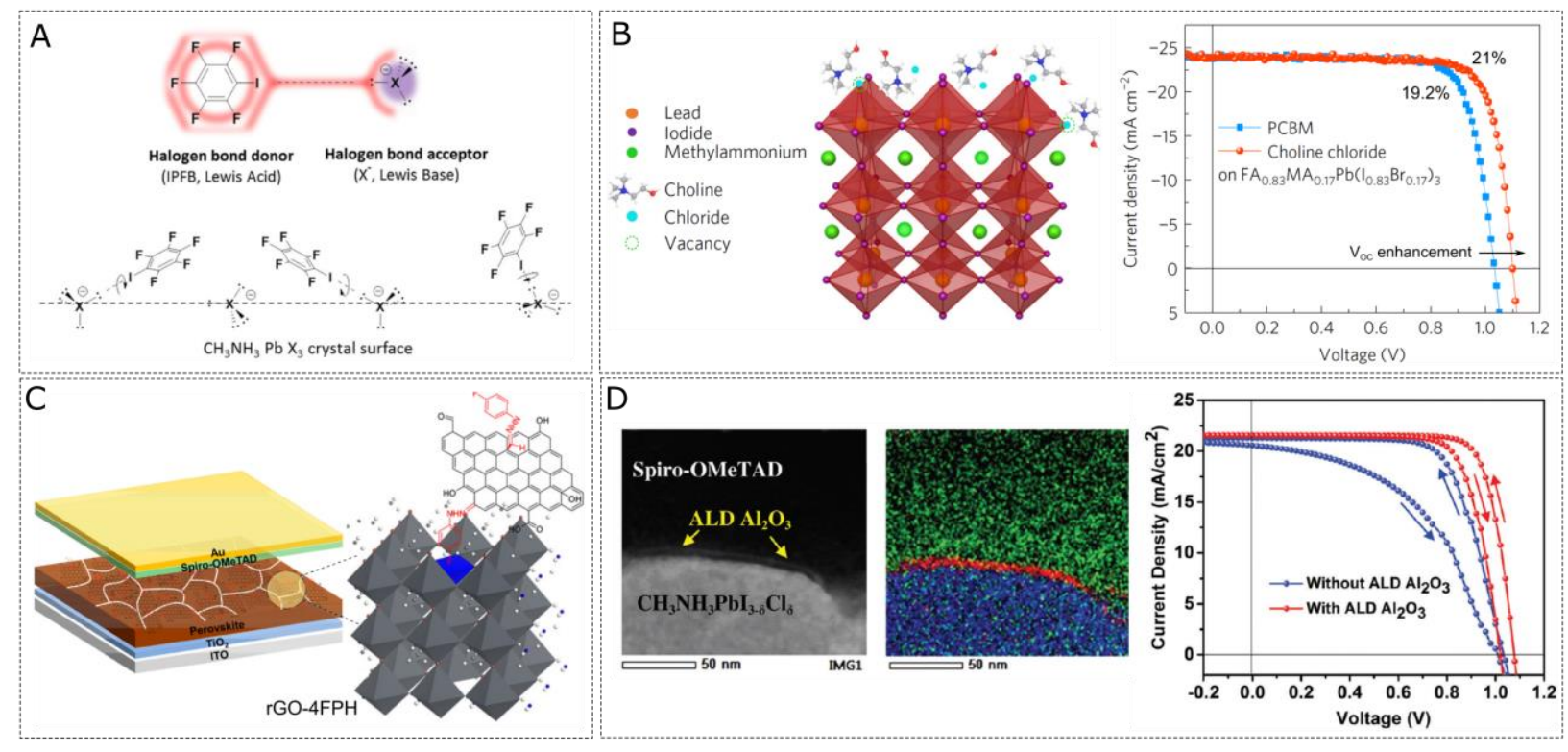

Figure 6. a) Schematic view of the halogen bond interaction between the IPFB (halogen bond donor), and a generic halogen anion $\left(\mathrm{X}^{-}=\mathrm{I}^{-}, \mathrm{Br}^{-}, \mathrm{Cl}^{-}\right.$, halogen bond acceptor with $\mathrm{sp}^{3}$-hybridized valence electrons. Schematic view of the IPFB assembly on the crystal surface. (Reproduced with permission ${ }^{[79]}$ ). b) Assembling quaternary ammonium halides on the defect sites (the red and blue symbols represent the $\mathrm{N}$ atom and $\mathrm{O}$ atom of the choline chloride molecule, respectively.) together with $\mathrm{J}-\mathrm{V}$ characteristics of the PSCs for control and with choline chloride passivation (Reproduced with permission ${ }^{[39]}$ ). c) Schematic of the possible passivation effect brought by rGO-4FPH together with J-V characteristics of the control and passivated PSCs (Reproduced with permission ${ }^{[90]}$ ). d) High angle annular dark field (HAADF) scanning TEM image of perovskite/Spiro-OMeTAD interface after $\mathrm{ALD}$ deposited $\mathrm{Al}_{2} \mathrm{O}_{3}$ passivation together with $\mathrm{J}-\mathrm{V}$ curve of control and passivated (10 cycles) (Reproduced with permission ${ }^{[91]}$ )

\subsubsection{Polymer Layer Capping}


Polymers are attractive for the passivation of vacancies on the perovskite surface. In general, the reported passivating polymers form bonds between the $\mathrm{H}$ atoms in alkylammonium of the perovskite (e.g., $\mathrm{MA}^{+}$) and $\mathrm{O}$ atoms in polymers, as well as by the strong interaction between lone pairs of electrons from $\mathrm{S}$ and $\mathrm{N}$ atoms in the polymer and $\mathrm{Pb}^{2+}$ ions in the perovskite crystal. Additionally, polymers can act as effective moisture barriers thanks to their hydrophobic nature, helping in enhanced device stability.

Lewis-base polymers which feature $(\mathrm{C}=\mathrm{O})$ groups can passivate under-coordinated $P b^{2+}$ atoms in the perovskite structure. For instance, poly(methyl methacrylate) (PMMA) has been introduced as a passivating polymer; its interaction with $\mathrm{PbI}_{2}$, with the formation of an intermediate adduct, was confirmed through FTIR analysis. ${ }^{[93],[94]}$ Indeed, the deposition of very thin PMMA overlayers on top of $\mathrm{MAPbI}_{3}$ enhances the PCE from 16.8 to $20.4 \%$ whereas the $\mathrm{V}_{\mathrm{OC}}$ is increased from 1.09 to $1.14 \mathrm{~V}$ by filling the surface and GB defects. ${ }^{[59,95]}$ PMMA passivation of both the perovskite/HTL and perovskite/ETL interfaces enables $\mathrm{V}_{\mathrm{OCS}}$ as high as $1.22 \mathrm{~V}$ for $\mathrm{E}_{\mathrm{g}}=1.60 \mathrm{eV}$ (Table 1). ${ }^{[96]}$ Poly(4-vinyl pyridine) (PVP) is another successful example within this group of polymers. ${ }^{[97]}$ A very thin $(<10 \mathrm{~nm})$ layer of PVP improves the $\mathrm{V}_{\mathrm{OC}}$ with $160 \mathrm{mV}$ by allowing the holes to tunnel while blocking the electron transfer at the perovskite/HTL interface. Meanwhile, thanks to the hydrophobic nature of the PVP, passivated devices also retained $85 \%$ of their initial PCE over 30 days in a 50\% humidity atmosphere whereas non-protected devices degraded easily. PVP blending with the $\mathrm{MAPbI}_{3}$ perovskite precursor provides ultrathin GB and surface coverage by thin polymer films. ${ }^{[98]}$ This treatment improved the $\mathrm{V}_{\mathrm{OC}}$ from 1.09 to $1.16 \mathrm{~V}$ and PCE from 18.02 to 20.23\%. Similar to surface passivation, PVP blending also helped to retain $85 \%$ of the PCE over 90 days, while the non-passivated cell completely degraded in 4 days. Alternatively, polystyrene (PS) has also been explored as a passivant for perovskite surfaces. ${ }^{[99]}$. A very thin 
layer of PS between the HTL and the perovskite can increase the PCE $>20 \%$, along with reduced hysteresis. Apart from hydrophobic polymers, hygroscopic polymers such as poly(ethylene oxide) (PEO) can be used as well for surface passivation, stabilizing the PSCs. ${ }^{[100]}$ Overall, these studies show the potential of polymers that interact with $P b^{2+}$ ions as good passivation-layer candidates. On the other hand, although polymer passivation enhances the $\mathrm{V}_{\mathrm{OC}}$, the insulating character of the polymer usually acts as a resistive interlayer on device level. Therefore, polymerpassivated PSCs usually show slightly lower FF values when compared with other passivants; see also data in Figure 2b. To enhance further the PCE of PSCs, more conductive polymers that can passivate multiple defects are required.

\subsubsection{D Perovskite Capping}

Two-dimensional (2D) layered Ruddlesden-Popper phase perovskites have been demonstrated to be more resilient to atmospheric degradation when compared to their traditional 3D counterparts. The typical 2D perovskites consist of inorganic layers of corner-sharing lead-iodide octahedra, confined between alkyl-ammonium cations. ${ }^{[101]}$ The conversion of the perovskite structure from 3D to 2D occurs by steric effects, by replacing the small organic cation with much larger organic cations. Using $n$-butylammonium (BA) spacer cations to form the (BA) $)_{2}(\mathrm{MA})_{3} \mathrm{~Pb}_{4} \mathrm{I}_{13} 2 \mathrm{D}$ perovskite absorber, higher than $12 \%$ PCEs have been reported, along with enhanced humidity tolerance. ${ }^{[102]}$ Nevertheless, the device performance of 2D-based PSCs lags behind its 3D counterparts, which most likely is due to the insulating nature of the organic cation interlayers, inhibiting out-of-plane charge transport through the contacts. ${ }^{[102]}$

Inserting a $2 \mathrm{D}$ or quasi-2D spacer between the $3 \mathrm{D}$ perovskite absorber and HTL can also be a method to passivate interfacial defects. Such layers are obtained when perovskites such as $\left(\mathrm{FAPbI}_{3}\right)_{0.88}\left(\mathrm{CsPbBr}_{3}\right)_{0.12}$ with excess $\mathrm{PbI}_{2}$ are exposed to 5-AVAI (5-ammoniumvaleric acid), 
forming the $2 \mathrm{D}(5-\mathrm{AVA})_{2} \mathrm{PbI}_{4}$ perovskite. ${ }^{[103]}$ The presence of $2 \mathrm{D}$ perovskite at the perovskite/HTL interface improves the $\mathrm{V}_{\mathrm{OC}}$ from 0.98 to $1.07 \mathrm{~V}$ and the PCE from 13.72 to 16.75\%. ${ }^{[103]}$ Alternatively, phenethylammonium iodide (PEA) can form an ultrathin 2D perovskite layer $\left(\mathrm{PEA}_{2} \mathrm{~Pb}_{2} \mathrm{I}_{4}\right)$ at perovskite surfaces and $\mathrm{GBs}$ which prevents moisture ingress by hydrophobic benzene groups of PEA. ${ }^{[104,105]} \mathrm{PL}$ analysis on 2D/3D mixed perovskites revealed that shortwavelength tails are observed when the samples are illuminated from the glass side (including ETL). This is indicative for the self-formation of 2D or quasi-2D perovskite interlayers. ${ }^{[105,106]}$ Benzylamine molecules have also been explored to suppress photo-induced degradation under heating at $85{ }^{\circ} \mathrm{C}$ by passivating surface and $\mathrm{GBs}$ with the $2 \mathrm{D}$ perovskite $\mathrm{BA}_{2} \mathrm{PbI}_{4}$. In addition to defect passivation, the presence of the $2 \mathrm{D}$ perovskite effectively blocks the ion migration path and removes those defect sites that may initiate decomposition and phase segregation, which often occurs in wide bandgap $\left(\mathrm{E}_{\mathrm{g}} \geq 1.72 \mathrm{eV}\right)$ perovskites. ${ }^{[87]}$ Recent studies showed that incorporation of $\mathrm{BA}^{+}$within cesium-formamidinium lead halide perovskite forms $2 \mathrm{D}$ interspersed perovskite layers between highly orientated 3D perovskite grains. ${ }^{[107]}$ This procedure enables increased power output of devices and preserves $80 \%$ of their initial efficiency after 1,000 hours in the air, and close to 4,000 hours when encapsulated. Mixed 2D/3D passivation by iso-butylammonium iodide ( $i \mathrm{BAI})$ results in a stabilized PCE of $21.7 \%$, along with excellent moisture resilience. ${ }^{[108]}$ (Figure 7a). A recent study explored the importance of the structural features of long organic cation on mixed perovskites for the stability of devices. ${ }^{[109]}$ By using long alkyl chains surfactants, individual grains can be encapsulated by 2D layers (Figure $7 \mathbf{b}$ ). The addition of a small amount of longchained octylammonium (OA) can provide such behavior, enhancing the PCE up to $20.6 \%$ compared to $18.4 \%$ of the control sample, together with increased humidity resistance. ${ }^{[109]}$ More 
detailed discussion on 2D-perovskite based passivation of the PSCs can be found in the comprehensive review by Grancini et al. ${ }^{[110]}$

Overall, these studies reveal that $2 \mathrm{D} / 3 \mathrm{D}$ perovskite structures acting as a selective surface passivant are promising to increase the stability of PSCs, combined with improved performance. Furthermore, thanks to preventing phase segregation in wide bandgap perovskites, capping by $2 \mathrm{D}$ perovskites can be the key for the development of stable, high-performance perovskite-based tandem solar cells, which require such wider bandgap perovskites.
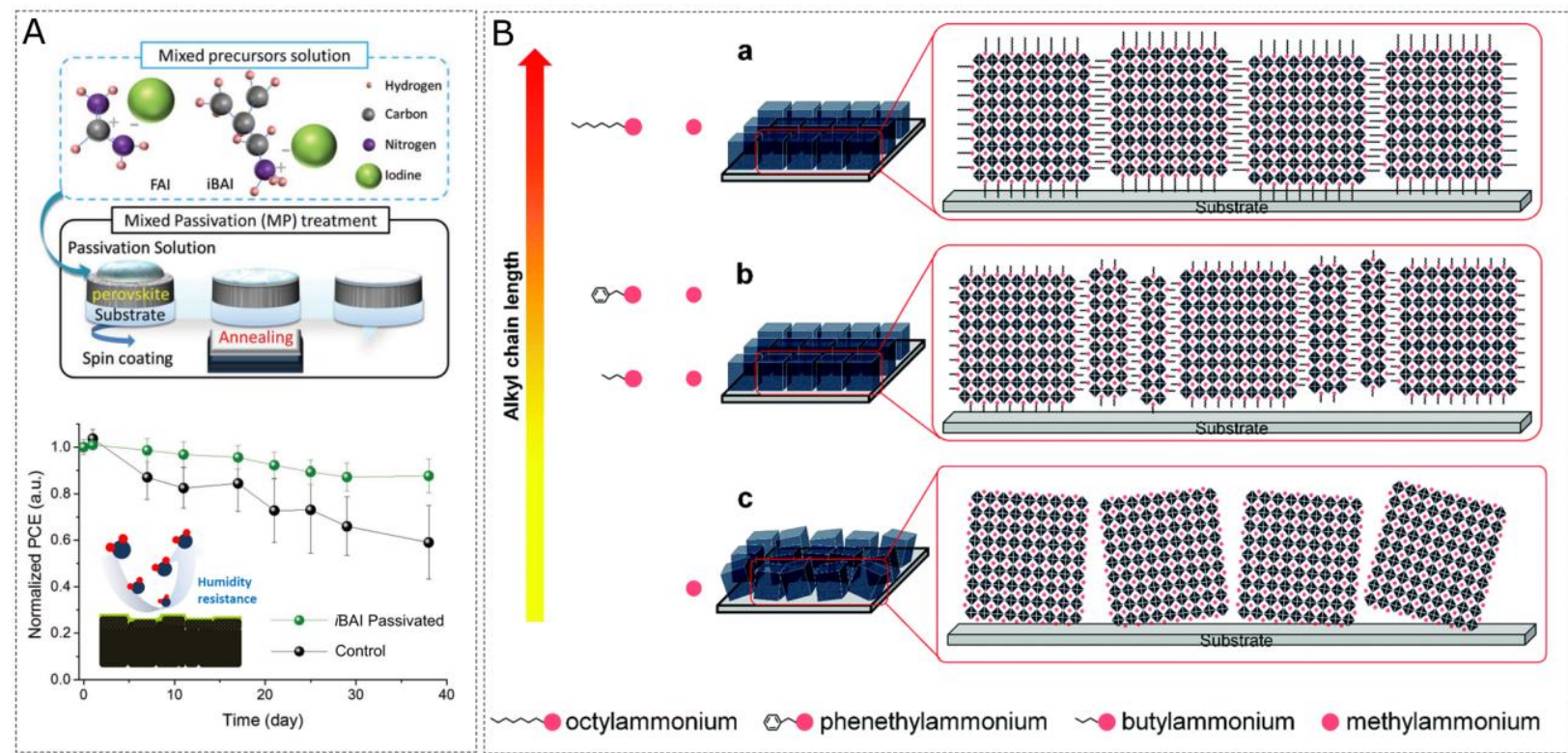

Figure 7. a) Schematic illustration of the self-assembled 2D/3D perovskite film structure after 2D perovskite formation with different chain lengths. (Reproduced with permission ${ }^{[109]}$ ) b) Schematic of the $i \mathrm{BAI}$ passivation treatment together with $\mathrm{J}-\mathrm{V}$ curves and stability graph of the passivated and non-passivated devices. (Reproduced with permission ${ }^{[108]}$ ) 
Table 1. Survey of some available passivation routes in the literature showing reduced hysteresis increased VOC of PSCs. (*,**)

\begin{tabular}{|c|c|c|c|c|c|c|c|c|c|}
\hline Passivation Method & Perovskite Absorber & $\begin{array}{c}\text { Device } \\
\text { Architecture }\end{array}$ & Sample & $\begin{array}{l}\text { VoC } \\
(\mathbf{V})\end{array}$ & $\begin{array}{c}\mathrm{JSC} \\
\left(\mathrm{mA} / \mathbf{c m}^{2}\right)\end{array}$ & $\begin{array}{l}\text { FF } \\
(\%)\end{array}$ & $\begin{array}{l}\text { PCE } \\
(\%)\end{array}$ & HI & Ref. \\
\hline \multicolumn{10}{|c|}{ Surface and Grain Boundary Passivation } \\
\hline \multirow{2}{*}{$\begin{array}{c}\text { Additive of } \\
\text { alkylphosphonic acid }\end{array}$} & \multirow{2}{*}{$\mathrm{MAPbI}_{3}$} & \multirow{2}{*}{$n-i-p$} & Control & 0.86 & 15.60 & 0.66 & 8.8 & 2.05 & \multirow{2}{*}{ [69] } \\
\hline & & & Passivated & 1.00 & 22.05 & 0.75 & 16.55 & 2.34 & \\
\hline \multirow{2}{*}{$\begin{array}{l}\text { Quaternary ammonium } \\
\text { halide anions and cations }\end{array}$} & \multirow{2}{*}{$\mathrm{FA}_{0.85} \mathrm{MA}_{0.15} \mathrm{~Pb}\left(\mathrm{I}_{0.85} \mathrm{Br}_{0.15}\right)_{3}$} & \multirow{2}{*}{$p-i-n$} & Control & 1.03 & 23.7 & 79 & 19.2 & - & \multirow{2}{*}{ [39] } \\
\hline & & & Passivated & 1.14 & 23.7 & 78 & 21.0 & 0 & \\
\hline \multirow{2}{*}{ PMMA passivation } & \multirow{2}{*}{$\mathrm{MAPbI}_{3}$} & \multirow{2}{*}{$n-i-p$} & Control & 1.11 & 20.9 & 73.1 & 16.8 & 1 & \multirow{2}{*}{ [95] } \\
\hline & & & Passivated & 1.14 & 23.4 & 76.6 & 20.4 & 1.7 & \\
\hline \multirow{2}{*}{$\begin{array}{c}\text { Non-stoichiometry } \\
\left.\text { (Excess } \mathrm{PbI}_{2}\right)\end{array}$} & \multirow{2}{*}{$\left(\mathrm{FAPbI}_{3}\right)_{1-x}\left(\mathrm{MAPbBr}_{3}\right)_{x}$} & \multirow{2}{*}{$n-i-p$} & Control & 1.06 & 23.05 & 74.86 & 18.37 & 5.7 & \multirow{2}{*}{ [64] } \\
\hline & & & Passivated & 1.13 & 23.69 & 76.40 & 21.52 & 1.5 & \\
\hline \multirow{2}{*}{$\begin{array}{c}\text { Ultrathin } \mathrm{Al}_{2} \mathrm{O}_{3} \text { layer } \\
\text { overlayer }\end{array}$} & \multirow{2}{*}{$\mathrm{MAPbI}_{3-\mathrm{x}} \mathrm{Cl}_{\mathrm{x}}$} & \multirow{2}{*}{$n-i-p$} & Control & 1.03 & 21.3 & 0.69 & 15.1 & 5.2 & \multirow{2}{*}{ [91] } \\
\hline & & & Passivated & 1.08 & 21.7 & 77.0 & 18.0 & 1.4 & \\
\hline \multirow{2}{*}{ 2D Perovskite capping } & \multirow{2}{*}{$\left(\mathrm{FAPbI}_{3}\right)_{0.88}\left(\mathrm{CsPbBr}_{3}\right)_{0.12}$} & \multirow{2}{*}{$n-i-p$} & Control & 0.99 & 21.13 & 66.0 & 13.72 & 3.7 & \multirow{2}{*}{ [103] } \\
\hline & & & Passivated & 1.07 & 21.93 & 72.0 & 16.75 & 1.3 & \\
\hline \multicolumn{10}{|l|}{ Contact Passivation } \\
\hline \multirow{2}{*}{ Cl-capping on $\mathrm{TiO}_{2}$} & \multirow{2}{*}{$\mathrm{Cs}_{0.05} \mathrm{FA}_{0.81} \mathrm{MA}_{0.14} \mathrm{PbI}_{2.55} \mathrm{Br}_{0.45}$} & \multirow{2}{*}{$n-i-p$} & Control & 1.13 & 21.6 & 76.0 & 18.5 & 4.5 & \multirow{2}{*}{ [111] } \\
\hline & & & Passivated & 1.19 & 22.30 & 80.6 & 21.4 & 0 & \\
\hline \multirow{2}{*}{ PMMA:PCBM on $\mathrm{TiO}_{2}$} & \multirow{2}{*}{$\mathrm{Cs}_{0.07} \mathrm{Rb}_{0.03} \mathrm{FA}_{0.765} \mathrm{MA}_{0.135} \mathrm{PbI}_{2.55} \mathrm{Br}_{0.45}$} & \multirow{2}{*}{$n-i-p$} & Control & 1.09 & 23.2 & 72.8 & 19.6 & 0.9 & [41] \\
\hline & & & Passivated & 1.16 & 23.10 & 76.2 & 20.4 & 0 & \\
\hline Double side passivation & & $n-i-p$ & Control & 1.11 & 22.85 & 77.0 & 19.50 & 1 & \\
\hline $\begin{array}{c}\text { (front PMMA:PCBM, } \\
\text { back PMMA) }\end{array}$ & $\mathrm{Cs}_{0.07} \mathrm{Rb}_{0.03} \mathrm{FA}_{0.765} \mathrm{MA}_{0.135} \mathrm{PbI}_{2.55} \mathrm{Br}_{0.45}$ & & Passivated & 1.20 & 22.60 & 76.4 & 20.8 & 0 & [96] \\
\hline MgO-protonated & & & Control & 1.09 & 18.31 & 73.5 & 18.31 & 1.45 & 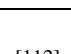 \\
\hline ethanolamine on $\mathrm{ZnO}$ & $(\mathrm{CsFAMA}) \mathrm{Pb}(\mathrm{BrI})_{3}$ & $n-i-p$ & Passivated & 1.12 & 23.86 & 78.9 & 21.08 & 0.17 & {$[112]$} \\
\hline
\end{tabular}

*All efficiency results are obtained from reverse scan bias direction.

$* * \mathrm{HI}: \Delta(P C E)=\left|R S_{(P C E)}-F S_{(P C E}\right|$ 


\section{WILEY-VCH}

\subsection{Contact Passivation}

PSCs can be fabricated either in the $n-i-p$ or $p-i-n$ device configuration; the first letter refers to which contact was deposited first, as sketched in Figure 8a. Beyond nomenclature, the device configuration influences several physical properties. Therefore, passivation techniques need to be specifically designed according to the type of contacts. In this section, we firstly discuss state-of the-art-contacts and give then an overview of the most successful contact passivation techniques.

\subsubsection{State-of-the-art contacts}

For the $n-i-p$ architecture, the electron-selective contacts are often mesoporous, which are mostly adapted from dye-sensitized solar cell (DSSC) technology. Indeed, early PSCs featured perovskite precursors fully infiltrating the micrometer-sized scaffold. ${ }^{[113],[114]}$ Soon, improved understanding of the device photophysics led to a gradual reduction of the scaffold thickness, from $10 \mu \mathrm{m}$ to only a few hundreds of nanometers ${ }^{[115]}$. The validity of this approach is also evidenced by the evolution of the record-device architectures over time. Currently, a stack of $60 \mathrm{~nm}$ of compact $\mathrm{TiO}_{2}\left(c-\mathrm{TiO}_{2}\right)$ covered by $\sim 150 \mathrm{~nm}$ of mesoporous $\mathrm{TiO}_{2}\left(m-\mathrm{TiO}_{2}\right)$ represents the most efficient ETL in PSCs as present in the device with the current certified PCE of $22.7 \% .^{[116]}$

Efficient PSCs can also be processed on planar ETLs without having a mesoporous scaffold. Due to the surface defects and limited interfacial area, $c-\mathrm{TiO}_{2}$ based PSCs often result in poor efficiencies. This can be improved by ionic-liquid modification of the $c$ - $\mathrm{TiO}_{2}$, which reportedly led to a certified PCE of $19.4 \% .^{[117]}$ Similarly, chlorine-capping of $\mathrm{TiO}_{2}$ nanoparticles as ETL resulted in a $20.1 \%$ certified PCE. ${ }^{[18]} \mathrm{ZnO}$ also has been argued to be a promising planar ETL thanks to its exceptionally high carrier mobility, high optical transparency, and ease of fabrication. ${ }^{[119]}$ However, direct deposition of the perovskite layer on $\mathrm{ZnO}$ shows poor chemical 


\section{WILEY-VCH}

stability and high hysteresis on device level, which implies that to achieve stable, high efficiencies, surface passivation is needed. Recently, 21.1\% hysteresis-free PSCs have been reported by modifying $\mathrm{ZnO}$ with magnesium oxide $(\mathrm{MgO})$ and protonated ethanolamine $(\mathrm{EA})$ via tuning the chemical interactions at the $\mathrm{ZnO}$ /perovskite interface. ${ }^{[112]} \mathrm{SnO}_{2}$ is another attractive ETL candidate for efficient PSCs thanks to its broadband transparency ( $E_{g}$ of $\left.3.6 \mathrm{eV}\right)$, combined with significantly higher mobility than $\mathrm{TiO}_{2 .}{ }^{[120-122]}$ Recently, numerous groups achieved more than 20\% PCE with a low-temperature solution-processed $\mathrm{SnO}_{2}$ ETL. ${ }^{[121,123]}$ Actually, with a $21.52 \%$ certified PCE, $\mathrm{SnO}_{2}$ is the most successful ETL for planar PSCs, to date. ${ }^{[124]}$ Notably, organic ETLs are usually unsuited for the realization of $n-i-p$ PSCs due to the high solubility of organic compounds in most of the commonly used perovskite solvents such as dimethylformamide (DMF) and dimethyl sulfoxide (DMSO). Nevertheless, cross-linked fullerene-based molecules may be able to overcome this issue. As an example, using crosslinked PCBM a PCE of $18.7 \%$ has been achieved. ${ }^{[125]}$

Although $n-i-p$ PSCs are leading the way in record efficiencies, the $p-i-n$ device architecture also enables high performance. The lack of solvent-compatible polymers and efficient $p$-type metal oxides has been are arguably the main causes inhibiting the rapid rise of $p-i$ - $n$ PSCs; for several years the HTL was essentially limited to PEDOT:PSS. However, notable improvements in device performance were obtained by introducing nickel oxide $\left(\mathrm{NiO}_{\mathrm{x}}\right)$ and copper thiocyanide $(\mathrm{CuSCN})$ as HTLs. Compared to PEDOT:PSS, $\mathrm{NiO}_{x}$, features a better bandalignment to the perovskite, enabling higher $\mathrm{V}_{\mathrm{OC}}$ values. ${ }^{[126,127]} \mathrm{A}$ bilayer of planar $\mathrm{NiO}_{\mathrm{x}}$ and mesoporous copper gallium oxide $\left(\mathrm{CuGaO}_{2}\right)$ also yielded efficiency of $\sim 20 \%$ with long-term stability. ${ }^{[128]}$ Recently, copper phthalocyanine $(\mathrm{CuPc})$ has been validated as a promising HTL with a PCE over $20 \%$ and good light stability. ${ }^{[129]}$ Currently, $p-i-n$ PSCs were reported with a PCE over 21\%, using poly[bis(4-phenyl)(2,4,6-trimethylphenyl)amine] (PTAA) as HTL. ${ }^{\text {[39] }}$ 


\section{WILEY-VCH}

Figure 8b shows the chronological evolution of the PCE of most reported device configurations sketches for the $n-i-p$ and $p-i-n$ device architectures.

\section{A}
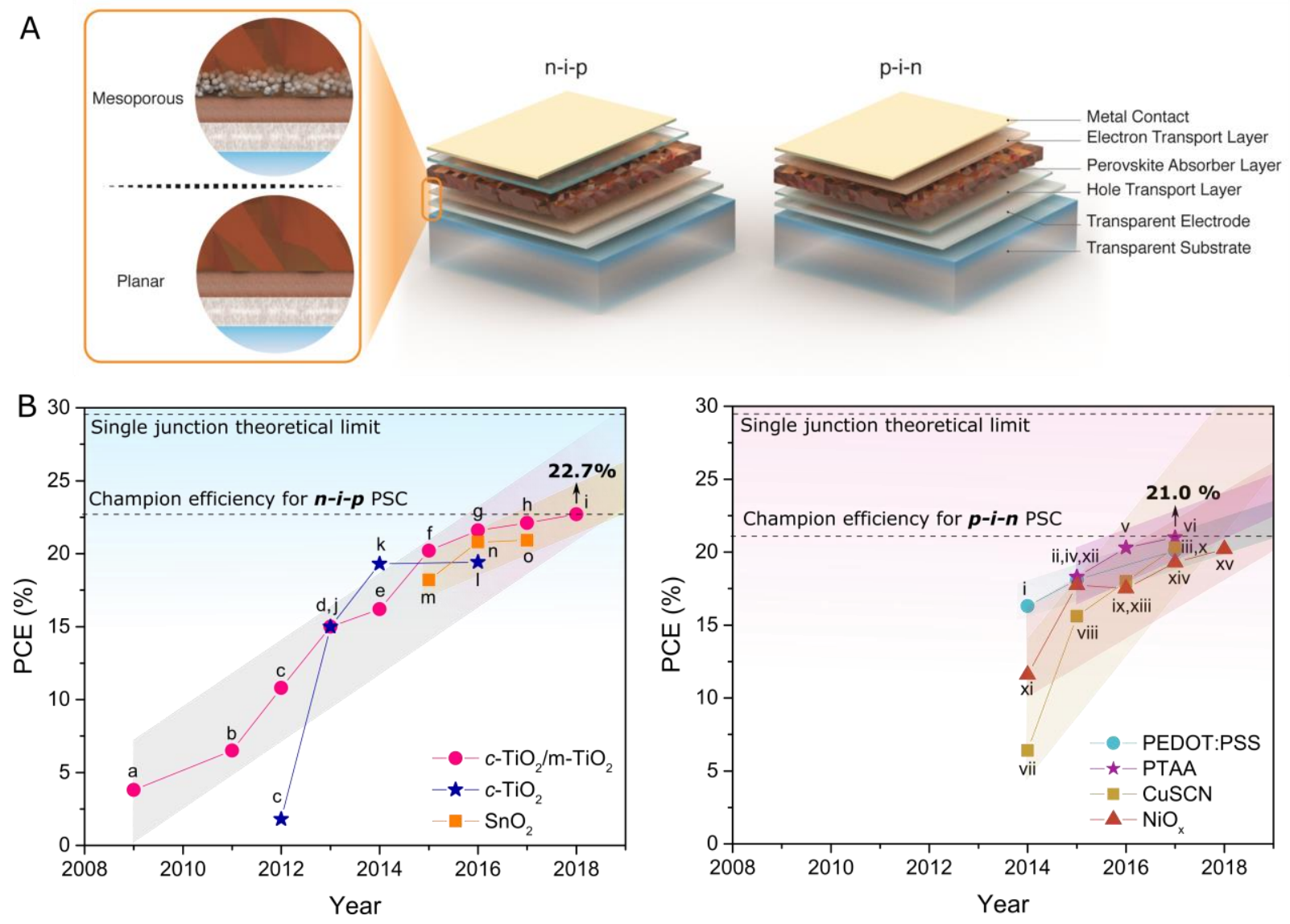

Figure 8. a) Schematic representation of $n-i-p$ and $p-i-n$ PSCs with a detailed view of the perovskite/ETL interface. b) The type of material employed in common devices is reported in the legend. Evolution of PSCs efficiency for $m-\mathrm{TiO}_{2}, c-\mathrm{TiO}_{2}, \mathrm{SnO}_{2}$, and $p-i-n$ devices. Results are taken from literature: $\mathrm{a}={ }^{[113]} ; \mathrm{b}={ }^{[114]} ; \mathrm{c}={ }^{[130]} ; \mathrm{d}={ }^{[131]} ; \mathrm{e}={ }^{[132]} ; \mathrm{f}={ }^{[133]} ; \mathrm{g}={ }^{[123]} ; \mathrm{h}==^{[116]} ; \mathrm{i}={ }^{[1]}$; $\mathrm{j}={ }^{[134]} ; \mathrm{k}={ }^{[117]} ; \mathrm{l}==^{[118]} ; \mathrm{m}==^{[120]} ; \mathrm{n}={ }^{[123]} ; \mathrm{o}={ }^{[64]} ; \mathrm{i}={ }^{[135]} ; \mathrm{ii}={ }^{[136]} ; \mathrm{iii}={ }^{[137]} ; \mathrm{iv}={ }^{[138]} ; \mathrm{v}==^{[139]} ; \mathrm{vi}={ }^{[39]}$; vii $={ }^{[140]} ; \mathrm{viii}={ }^{[141]} ; \mathrm{ix}={ }^{[142]} ; \mathrm{x}={ }^{[143]} ; \mathrm{xi}={ }^{[144]} ; \mathrm{xii}={ }^{[145]} ; \mathrm{xiii}={ }^{[146]} ; \mathrm{xiv}={ }^{[147]} ; \mathrm{xv}={ }^{[148]}$.

\subsubsection{Charge-Transport Layers: Bulk Passivation}

The reason why some contact structures result in better device performance than others is not yet fully understood, either for the $n-i-p$ or $p-i-n$ architectures. Early works argued that the energetic alignment between the contact and perovskite absorber layers as the main factors dictating the performance of the PSCs. More recently, the absence of carrier transport barriers along the different interfaces, from perovskite towards the external electrodes, is seen as the most important contact property. The champion performance of the $c-\mathrm{TiO}_{2} / m-\mathrm{TiO}_{2}$ stack ETLs have been achived from the continuousoptimization of its scaffold properties, with specific 


\section{WILEY-VCH}

attention for the defects. This can be taken as an inspiration when developing new contacting materials.

In the defective $\mathrm{TiO}_{2}$ crystals, the absence of one neutral $\mathrm{O}$ atom leaves one point defect and two under-coordinated $\mathrm{Ti}^{3+}$ atoms (Figure 9a and 9b). This results in a localized vacancy state, positioned at $0.75-1.18 \mathrm{eV}$ below the conduction band. ${ }^{[149]}$ This defect level essentially acts as an electron trap. Its density increases with increasing $\mathrm{O}$ vacancy density, both for the rutile and anatase phases; ultimately these levels merge with the conduction band of $\mathrm{TiO}_{2}$. A similar understanding of defects was recently developed for flat $\mathrm{SnO}_{2}$. Here, a sub-stoichiometry in $\mathrm{O}$ induces again intrinsic defects, in the form of $\mathrm{O}$ vacancies, giving the material its characteristic n-type behavior. ${ }^{[150]}$ A summary of the most common defects in $\mathrm{TiO}_{2}, \mathrm{SnO}_{2}$ are shown in Figure 9b and 9c.
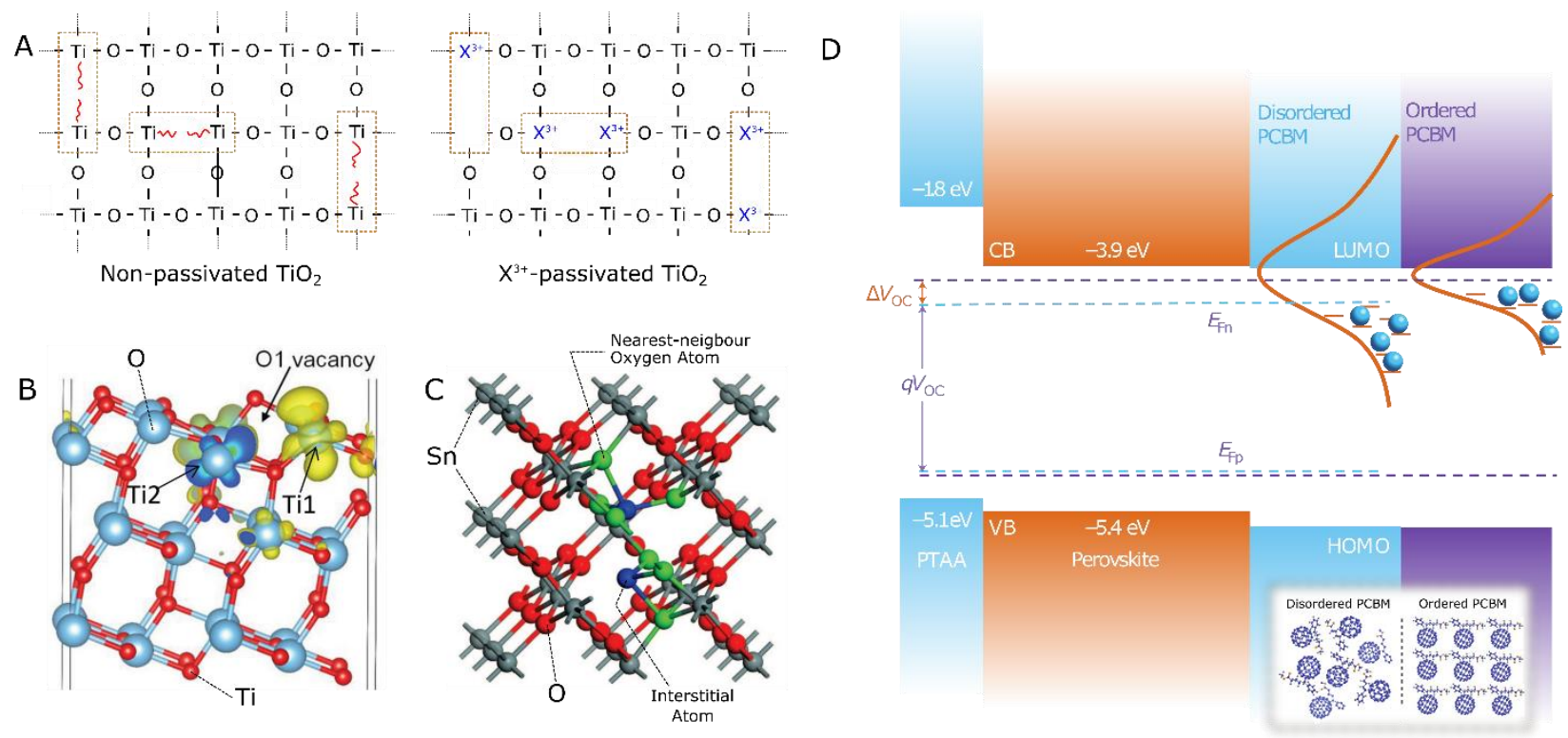

Figure 9. a) Example of $\mathrm{O}$ vacancy and passivation of these defects +3 valency atoms (Reproduced with permission ${ }^{[151]}$ ), b) illustration of $\mathrm{O}$ vacancy defects on the surface $\mathrm{TiO}_{2}$ (Reproduced with permission ${ }^{[152]}$ ), c) Sn interstitial in $\mathrm{SnO}_{2}$ lattice. In blue are represented interstitial atoms, in green nearest-neighbor $\mathrm{O}$ atom, in red $\mathrm{O}$, in the gray $\mathrm{Sn}$ (Reproduced from $\left.{ }^{[150]}\right)$. d) Schematic illustration of energy disorder influence on the $\mathrm{V}_{\mathrm{OC}}$ of a $p-i$ - $n$ device. The purple and blue dashed lines are the electron and hole quasi-Fermi levels of devices with ordered and disorder PCBM layer, respectively (Reproduced with permission ${ }^{[153]}$ ). 


\section{WILEY-VCH}

Trap-filling and $\mathrm{O}$ desorption from the crystal lattice are promising methods to increase the conductivity of $\mathrm{TiO}_{2}$ layers. To facilitate these processes, heteroatom doping can be a simple method to modify the electronic properties of the $\mathrm{TiO}_{2}$. Indeed, a work function (WF) reduction (i.e., towards $n$-type character) is observed in $\mathrm{TiO}_{2}$ doped by penta (or greater) valent ions, whereas a WF increase (i.e., towards $p$-type character) is observed when doping with lower valence ions. ${ }^{[151]}$ Accordingly, extrinsic dopants with +3 valence have been reported to provide effective passivation of $\mathrm{TiO}_{2}$ by suppressing unwanted trap states. ${ }^{[154],[151]}$ For example, $\mathrm{Al}^{3+}$ can be incorporated within the $\mathrm{TiO}_{2}$ lattice as interstitial, substitutional to $\mathrm{Ti}^{4+}$, or both since the ionic radius of $\mathrm{Al}^{3+}$ is close to that of $\mathrm{Ti}^{4+}$ and $\mathrm{Ti}^{3+} \cdot{ }^{[151,155]} \mathrm{Ab}$ initio calculations indicate that the substitution of two $\mathrm{Ti}^{4+}$ with $\mathrm{Al}^{3+}$ shows thermodynamically and electronically more favorable characteristics than a single O-vacancy. ${ }^{[156]}$ Indeed, through this mechanism, Odefects can be excluded from the $\mathrm{TiO}_{2}$ lattice without generating additional defect levels. Additionally, doping with $\mathrm{Al}^{3+}$ causes an upward shift of the $\mathrm{CBM}$, increasing the $\mathrm{E}_{\mathrm{g}}$ of $\mathrm{TiO}_{2 .}{ }^{[151]}$ Indium is another dopant with +3 valence, with the potential to passivate electronic defects originated from non-stoichiometric $\mathrm{O}$ within the $\mathrm{TiO}_{2}$ lattice. ${ }^{[154]}$ Moreover, In-doping increases the conductivity of $c-\mathrm{TiO}_{2}$, resulting in devices with $\mathrm{FF}$ values close to $\sim 80 \%$. Lastly, In-doping improves the electrical properties of the perovskite/ $\mathrm{TiO}_{2}$ interface by the upward shifting of the CBM of the $c-\mathrm{TiO}_{2}$ layer. Similar upward shifting of the CBM and increased conductivity can be obtained by $\mathrm{Y}$ doping of $c$-TiO layer. $^{[157]}$ Interestingly, Li-doping of the surface of the $c-\mathrm{TiO}_{2}$ can facilitate faster electron transport by partial reduction of $\mathrm{Ti}^{4+}$ to $\mathrm{Ti}^{3+}{ }^{[158]}$ Thanks to the passivation of the surfaces defects, the Li-treated devices show overall better performance with higher $\mathrm{V}_{\mathrm{OC}}$, compared to the untreated references. A summary of some reported results for $\mathrm{TiO}_{2}$ passivation is presented in Table 2. 


\section{WILEY-VCH}

Table 2. Successful heteroatom doping in literature as defects passivation of $\mathrm{TiO}_{2}$ for $\mathrm{PSC}$ applications.

\begin{tabular}{|c|c|c|c|c|c|c|c|c|}
\hline Dopant & & Voc & Jsc & FF & PCE & WF & & Ref \\
\hline \multirow[t]{2}{*}{ In } & Control & 1.10 & 22.9 & 74.5 & 18.8 & -4.22 & CsMAFAPbIBr & [154] \\
\hline & Doped & 1.10 & 23.1 & 79.1 & 20.1 & -4.00 & & \\
\hline \multirow[t]{2}{*}{$\mathbf{Y t}$} & Control & 1.10 & 21.82 & 72.9 & 17.50 & -4.08 & CsMAFAPbIBr & [157] \\
\hline & Doped & 1.10 & 23.24 & 78.2 & 19.99 & -3.95 & & \\
\hline \multirow[t]{2}{*}{$\mathbf{L i}$} & Control & 1.04 & 22.7 & 72 & 17.1 & l & MAFAPbIBr & {$[158]$} \\
\hline & Doped & 1.11 & 23.0 & 74 & 19.3 & I & & \\
\hline
\end{tabular}

Even in fullerene-based ETLs, material disorder such as low crystallinity, random molecular orientations, and impurities can generate intermediate gap states, with a broadly distributed density of states (DOS) (Figure 9d) ${ }^{[153]}$ Such defect states may result in recombination losses in the perovskite and thus decreased $\mathrm{V}_{\mathrm{OC}}$ on device level. Ordered PCBM is found to feature a lower concentration of intermediate states with a narrower distributed DOS, compared to disordered PCBM, which results in $100 \mathrm{mV}$ enhanced VOC. ${ }^{[153]}$ Other polymer-based ETLs and HTLs also require reduced disorder to enable enhanced $V_{\text {OC. }}$ These studies highlight the urgency of developing new charge-transport layers with high structural order and the capability of passivating the defects within such films.

\subsubsection{Charge-Transport Layers: Interfacial Passivation}

The presence of dangling bonds on the surface of ETLs or HTLs generates trap states at their interface with the perovskite, causing recombination and reducing the PCE. Moreover, surface defects of such layers may act as crystallization sites, which can undesirably affect perovskite nucleation. This motivates the development of interlayer materials and methods for contact passivation. The main limiting factors for the development of passivation layers are given by the (limited) choice of solvents that is compatible with the perovskite solvents and by the maximum annealing temperature that is compatible with the device fabrication. Accordingly, 


\section{WILEY-VCH}

$\mathrm{C}_{60}$ self-assembled monolayers (SAM) is found to be robustly anchored to the $m-\mathrm{TiO}_{2}$ scaffold and resistant to the perovskite solvents. ${ }^{[159,160]}$ Indeed, anchoring the $\mathrm{C}_{60}-\mathrm{SAM}$ to $c$ - $\mathrm{TiO}_{2}$ via benzoic acid group, yields an increased PCE with suppressed hysteresis. ${ }^{[160]}$ This improved performance is attributed to a reduced DOS at the $\mathrm{TiO}_{2}$ surface, resulting in less recombination at the perovskite/ $\mathrm{TiO}_{2}$ interface. Alternatively, passivating $\mathrm{ZnO}$ with $\mathrm{SAM}$ obtained from 3aminopropanioc acid $\left(\mathrm{C}_{3}\right.$-SAM) enhances the morphology of the perovskite and also improves the energy alignment between the $\mathrm{ZnO}$ layer and the perovskite. ${ }^{[161]}$ Overall, this treatment improved the PCE from 11.96 to $15.67 \%$. With the same technique, a $\sim 10 \%$ relative PCE improvement compared with the untreated sample was achieved by treating the surface of $\mathrm{SnO}_{2}$ with SAM of pyridinecarboxylic acid. ${ }^{[162]}$ Similar to the passivation of perovskite surfaces, ultrathin metal oxides can also be used for passivation of ETL and HTL surfaces. The presence of the wide bandgap ultrathin metal oxide layer suppresses interfacial charge recombination. For instance, ultrathin $\mathrm{ALD} \mathrm{Al}_{2} \mathrm{O}_{3}$ effectively passivates the $c-\mathrm{TiO}_{2} / m-\mathrm{TiO}_{2}$ interface, enhancing the $\mathrm{J}_{\mathrm{SC}}$ and $\mathrm{FF} .{ }^{[163]}$ In another study, a sol-gel deposited nano-layer of $\mathrm{MgO}$ on top of the $\mathrm{TiO}_{2}$-nanoparticles ETL provides enhanced $\mathrm{V}_{\mathrm{OC}}$ and $\mathrm{FF}^{[164]}$ Following this direction, lantanum oxide $\left(\mathrm{La}_{2} \mathrm{O}_{3}\right)$ modification of the $m-\mathrm{TiO}_{2}$ scaffold resulted in a $110 \mathrm{mV}$ increase in $\mathrm{V}_{\mathrm{OC}}$, along with an increase of the PCE from $9.43 \%$ to $15.81 \%{ }^{[165]}$ Another interesting modification of the $m-\mathrm{TiO}_{2}$ layer consists of incorporating cesium bromide $(\mathrm{CsBr})$ in the dense scaffold of $\mathrm{TiO}_{2}$ nanoparticles. ${ }^{[166]}$ The inclusion of $\mathrm{CsBr}$ facilitates charge extraction from the scaffold by reducing carrier recombination, which is consistent with an enhancement in $\mathrm{V}_{\text {OC }}$ of $40 \mathrm{mV}$. Inorganic binary alkaline halides (e.g., $\mathrm{KI}, \mathrm{KCl}$ ) are also good passivants for $\mathrm{SnO}_{2} \mathrm{ETLs}$ by passivating both positively and negatively charged ionic defects at perovskite/ETL interface. $\mathrm{KCl}$ treatment of $\mathrm{SnO}_{2}$ provides $100 \mathrm{mV} \mathrm{V}$ OC enhancement and PCEs up to 20.5\%, together with negligible hysteresis behavior. ${ }^{[167]}$ 


\section{WILEY-VCH}

Passivation of the perovskite/HTL interface is studied in the $p-i-n$ architecture as well. To enhance the $V_{O C}$ of the PSCs, the surface modification of PEDOT: PSS has been widely studied. ${ }^{[168]}$ Later, $\mathrm{NiO}_{\mathrm{x}}$ was also found to be a promising HTL, but featuring surface defects such as highly reactive $\mathrm{O}$ dangling bonds induced by Ni vacancies. ${ }^{[127,169]}$ Several studies on passivating such specific defect haves been reported previously. ${ }^{[170]}$ However, exceeding the 20\% PCE with $\mathrm{NiO}_{\mathrm{x}}$ HTLs still requires surface passivation schemes that are waiting to be explored. Lastly, PTAA, which is giving the highest PCE for $p-i-n$ configuration PSCs to date, also likely benefits from proper passivation schemes. Some important device parameters have been summarized in Table 1 for selected surface passivation schemes of the charge transport layers.

In summary, all the techniques discussed here systematically improved device performance, highlighting the importance of passivation. We note that the $\mathrm{V}_{\mathrm{OC}}$ represents the most evident parameter that benefits from passivation since it directly relates to the reduction of non-radiative recombination processes. However, the FF of devices is perhaps an even more critical parameter to be considered. Here, the challenge evidently is to find structures that combine low recombination with low (contact) resistance. Overall, there is still a wide choice of materials to be explored that may fit all needed criteria for successful integration in devices: zirconium oxide $\left(\mathrm{ZrO}_{2}\right)$, niobium oxide $\left(\mathrm{Nb}_{2} \mathrm{O}_{5}\right)$, and yttrium oxide $\left(\mathrm{Y}_{2} \mathrm{O}_{3}\right)$ are satisfactory examples from the heritage of liquid or solid-state DSSCs, since most of these materials suppress interfacial recombination at the primary metal oxide electrode. Moreover, new types of charge selective contacts (such as metal nitrides) are also waiting to be explored for applications in perovskite solar cells. $^{[171]}$ 


\section{WILEY-VCH}

\section{Outlook}

A better understanding of the surface and interfaces of polycrystalline perovskites, combined with the development of rational passivation routes are needed to fully unlock the high intrinsic electronic quality offered by perovskites. These are essential steps to approach the ShockleyQueisser performance limit, as well as to increase the stability of devices, which will be critical for possible market entry of perovskites. So far, the majority of the reported passivation techniques have been empirical. Although an increasingly wide spectrum of materials and techniques has been reported to reduce carrier recombination in perovskite materials and devices, quantifying the defects that are causing recombination remains challenging. Exploring new and rapid spectroscopic and modeling techniques specifically geared toward understanding the passivation effect might be important in such work. Typical electrical characterization of microelectronic semiconductors can find difficult applications with perovskites, due to the characteristic ion migration and alteration of optoelectronic properties under an external electric field. Nevertheless, space-charged limited current (SCLC) was used in many reports to quantify traps densities in perovskite single crystals and later by others for thin films. However, quantifying the density of the defects precisely before and after passivation is even more challenging from an experimental point of view. In this direction, DLTS measurements give fruitful insight. Still, due to the intrinsic nature of perovskites, quantifying the capture cross section of minority carriers remains an open challenge. Finally, many works referred to PL (either time-resolved or steady state) as a useful tool to qualitatively investigate the perovskite defects. However, PL investigations are limited to radiative recombination, leaving the nonradiative component an open challenge.

On device level, the most critical parameter is arguably FF, which demands (passivating) contact stacks that simultaneously lead to low resistive and recombination losses. Taking inspiration from this point, a deeper understanding of factors that contribute to the contact 


\section{WILEY-VCH}

resistivity of perovskite devices (such as Fermi-level pinning, the presence of thermionic barriers, as well the importance of chemical versus field-effect passivation) may give critical insights and lead the way to new types of contact stacks. Additional criteria to be considered for effective contact stacks is the minimizing of parasitic light absorption and maximizing of light coupling into the perovskite absorber. To fulfil these, engineering of the optical properties of the passivating contact stack will be of extreme importance, especially for ultra-high efficiency devices such as perovskite-based tandem cells.

As stated, long-term stability of perovskite devices is another sought-after milestone if this technology aims to enter the conventional PV market. In this review, we presented passivation routes that result in increased device lifetimes on the shelf and under accelerated degradation conditions. For commercialization, $\mathrm{Pb}$-free perovskites, using $\mathrm{Sn}$ (or others) as a divalent cation, may be necessary. This change will raise new concerns regarding the passivation of defects originating from $\mathrm{O}$-sensitive $\mathrm{Sn}^{2+}$ cations. Therefore, passivation of Sn-containing perovskites also should be considered. Besides this, scaling-up of perovskite solar cells requires large-area compatible deposition techniques; vacuum-based deposition techniques can here be counted to be particularly attractive. To approach market readiness, more realistic stability tests will also be required to further prove the effectiveness of passivation techniques.

Next, most currently reported passivation techniques in the literature target the healing of only one specific defect. For long-term stability, research needs to focus on complete, 'holistic' passivation schemes, including bulk, contact, interface, and GB passivation. Finally, we point out the passivation schemes highlighted in this review can also be utilized for performance improvement of perovskite-based, light-emitting diodes, field-effect transistors, and other electronic devices.

\section{Acknowledgments}




\section{WILEY-VCH}

This study was supported by funding from King Abdullah University of Science and Technology (KAUST) Office of Sponsored Research (OSR) under award no. OSR-CARF URF/1/3079-33-01. Figure 3 and Figure 8. a was created by Heno Hwang, scientific illustrator at KAUST.

Received: ((will be filled in by the editorial staff))

Revised: ((will be filled in by the editorial staff)) Published online: ((will be filled in by the editorial staff))

\section{References}

[1] NREL Efficiency Chart Vol. 2018, https://www.nrel.gov/pv/assets/pdfs/pv-efficiencychart.20190103.pdf., accessed: 01-2019.

[2] S. De Wolf, J. Holovsky, S. J. Moon, P. Loper, B. Niesen, M. Ledinsky, F. J. Haug, J. H. Yum, C. Ballif, J. Phys. Chem. Lett. 2014, 5, 1035.

[3] R. R. King, D. Bhusari, A. Boca, D. Larrabee, X.-Q. Liu, W. Hong, C. M. Fetzer, D. C. Law, N. H. Karam, Prog. Photovoltaics 2011, 19, 797.

[4] M. Saliba, T. Matsui, K. Domanski, J.-Y. Seo, A. Ummadisingu, S. M. Zakeeruddin, J.-P. Correa-Baena, W. R. Tress, A. Abate, A. Hagfeldt, M. Grätzel, Science 2016, 354, 206.

[5] W. Tress, Adv. Energy Mater. 2017, 7, 1602358.

[6] M. Taguchi, A. Yano, S. Tohoda, K. Matsuyama, Y. Nakamura, T. Nishiwaki, K. Fujita, E. Maruyama, IEEE J. Photovolt. 2014, 4, 96.

[7] K. Yoshikawa, H. Kawasaki, W. Yoshida, T. Irie, K. Konishi, K. Nakano, T. Uto, D. Adachi, M. Kanematsu, H. Uzu, K. Yamamoto, Nat. Energy 2017, 2, 17032.

[8] P. M. P. Salomé, B. Vermang, R. Ribeiro-Andrade, J. P. Teixeira, J. M. V. Cunha, M. J. Mendes, S. Haque, J. Borme, H. Águas, E. Fortunato, R. Martins, J. C. González, J. P. Leitão, P. A. Fernandes, M. Edoff, S. Sadewasser, Adv. Mater. Interfaces 2018, 5, 1701101; B. Vermang, Y. Ren, O. Donzel-Gargand, C. Frisk, J. Joel, P. Salomé, J. Borme, S. Sadewasser, C. Platzer-Björkman, M. Edoff, IEEE J. Photovolt. 2016, 6, 332; M. O. Reese, C. L. Perkins, J. M. Burst, S. Farrell, T. M. Barnes, S. W. Johnston, D. Kuciauskas, T. A. Gessert, W. K. Metzger, J Appl Phys 2015, 118; B. Bissig, C. Guerra-Nunez, R. Carron, S. 


\section{WILEY-VCH}

Nishiwaki, F. La Mattina, F. Pianezzi, P. A. Losio, E. Avancini, P. Reinhard, S. G. Haass, M.

Lingg, T. Feurer, I. Utke, S. Buecheler, A. N. Tiwari, Small 2016, 12, 5339.

[9] M. B. Johnston, L. M. Herz, Accounts of Chemical Research 2016, 49, 146; R. L.

Milot, R. J. Sutton, G. E. Eperon, A. A. Haghighirad, J. Martinez Hardigree, L. Miranda, H. J.

Snaith, M. B. Johnston, L. M. Herz, Nano Lett. 2016, 16, 7001.

[10] F. Staub, H. Hempel, J.-C. Hebig, J. Mock, U. W. Paetzold, U. Rau, T. Unold, T. Kirchartz, Phys. Rev. Appl.2016, 6, 044017.

[11] J. M. Richter, M. Abdi-Jalebi, A. Sadhanala, M. Tabachnyk, J. P. H. Rivett, L. M. Pazos-Outón, K. C. Gödel, M. Price, F. Deschler, R. H. Friend, Nat. Commun. 2016, 7; C. L. Davies, M. R. Filip, J. B. Patel, T. W. Crothers, C. Verdi, A. D. Wright, R. L. Milot, F. Giustino, M. B. Johnston, L. M. Herz, Nat. Commun. 2018, 9, 293.

[12] A. Descoeudres, Z. C. Holman, L. Barraud, S. Morel, S. De Wolf, C. Ballif, IEEE J. Photovolt. 2013, 3, 83.

[13] C. Battaglia, A. Cuevas, S. De Wolf, Energy Environ. Sci. 2016, 9, 1552.

[14] S. H. Song, K. Nagaich, E. S. Aydil, R. Feist, R. Haley, S. A. Campbell, "Structure optimization for a high efficiency CIGS solar cell", presented at $201035^{\text {th }}$ IEEE Photovoltaic Specialists Conference, 20-25 June 2010, 2010; Y. Y. Proskuryakov, K. Durose, J. D. Major, M. K. Al Turkestani, V. Barrioz, S. J. C. Irvine, E. W. Jones, Sol. Energy Materials and Solar Cells 2009, 93, 1572; S. D. Stranks, ACS Energy Lett. 2017, 2, 1515.

[15] D. W. de Quilettes, S. M. Vorpahl, S. D. Stranks, H. Nagaoka, G. E. Eperon, M. E. Ziffer, H. J. Snaith, D. S. Ginger, Science 2015, 348, 683.

[16] F. Pianezzi, P. Reinhard, A. Chirilă, S. Nishiwaki, B. Bissig, S. Buecheler, A. N. Tiwari, Journal of Applied Physics 2013, 114, 194508; A. A. B. Baloch, M. I. Hossain, N. Tabet, F. H. Alharbi, J. Phys. Chem. Lett. 2018, 9, 426; H. Elhadidy, J. Franc, P. Moravec, P. Höschl, M. Fiederle, Semiconductor Science and Technology 2007, 22, 537; J. H. Zhao, T. E. Schlesinger, A. G. Milnes, Journal of Applied Physics 1987, 62, 2865; G. Landi, H. C. 


\section{WILEY-VCH}

Neitzert, C. Barone, C. Mauro, F. Lang, S. Albrecht, B. Rech, S. Pagano, Adv. Sci. 2017, 4; A. Y. Polyakov, N. B. Smirnov, I. V. Shchemerov, D. S. Saranin, T. S. Le, S. I. Didenko, D. V. Kuznetsov, A. Agresti, S. Pescetelli, F. Matteocci, A. D. Carlo, Applied Physics Letters 2018, $113,263501$.

[17] Y. Yang, M. Yang, Y. Yan, K. Zhu, Nat. Energy. 2017, 2, 1.

[18] Y. Yang, Y. Yan, M. Yang, S. Choi, K. Zhu, J. M. Luther, M. C. Beard, Nat. Commun. 2015, 6, 7961.

[19] M. Hafemeister, S. Siebentritt, J. Albert, M. C. Lux-Steiner, S. Sadewasser, Physical Review Letters 2010, 104, 196602; G. Y. Kim, A. R. Jeong, J. R. Kim, W. Jo, D.-H. Son, D.H. Kim, J.-K. Kang, Sol. Energy Materials and Solar Cells 2014, 127, 129; J. B. Li, V. Chawla, B. M. Clemens, Adv. Mater. 2012, 24, 720.

[20] I. Visoly-Fisher, S. R. Cohen, K. Gartsman, A. Ruzin, D. Cahen, Adv. Func. Mater. 2006, 16, 649 .

[21] W.-J. Yin, T. Shi, Y. Yan, Adv. Mater. 2014, 26, 4653.

[22] J. S. Yun, A. Ho-Baillie, S. Huang, S. H. Woo, Y. Heo, J. Seidel, F. Huang, Y.-B. Cheng, M. A. Green, J. Phys. Chem. Lett. 2015, 6, 875.

[23] R. Long, J. Liu, O. V. Prezhdo, J. Am. Chem. Soc. 2016, 138, 3884.

[24] W.-J. Yin, H. Chen, T. Shi, S.-H. Wei, Y. Yan, Adv. Electron. Mater. 2015, 1, 1500044.

[25] T. S. Sherkar, C. Momblona, L. Gil-Escrig, J. Ávila, M. Sessolo, H. J. Bolink, L. J. A. Koster, ACS Energy Lett. 2017, 2, 1214.

[26] G. W. P. Adhyaksa, S. Brittman, H. Āboliņ̌s, A. Lof, X. Li, J. D. Keelor, Y. Luo, T.

Duevski, R. M. A. Heeren, S. R. Ellis, D. P. Fenning, E. C. Garnett, Adv. Mater., 0, 1804792.

[27] J. Huang, Y. Shao, Q. Dong, J. Phys. Chem. Lett. 2015, 6, 3218.

[28] W. Nie, H. Tsai, R. Asadpour, J.-C. Blancon, A. J. Neukirch, G. Gupta, J. J. Crochet, M. Chhowalla, S. Tretiak, M. A. Alam, H.-L. Wang, A. D. Mohite, Science 2015, 347, 522; 


\section{WILEY-VCH}

W. S. Yang, J. H. Noh, N. J. Jeon, Y. C. Kim, S. Ryu, J. Seo, S. I. Seok, Science 2015, 348, 1234; Z. Xiao, Q. Dong, C. Bi, Y. Shao, Y. Yuan, J. Huang, Adv. Mater. 2014, 26, 6503.

[29] E. Ugur, A. D. Sheikh, R. Munir, J. I. Khan, D. Barrit, A. Amassian, F. Laquai, ACS Energy Lett. 2017, 2, 1960.

[30] H. D. Kim, H. Ohkita, H. Benten, S. Ito, Adv. Mater. 2016, 28, 917.

[31] PVCDROM, http://pvcdrom.pveducation.org/SEMICON/ABSDEPTH.HTM, accessed: 01, 2018.

[32] J. Jean, T. S. Mahony, D. Bozyigit, M. Sponseller, J. Holovský, M. G. Bawendi, V. Bulović, ACS Energy Lett. 2017, 2, 2616.

[33] J. T.-W. Wang, Z. Wang, S. Pathak, W. Zhang, D. W. deQuilettes, F. WisniveskyRocca-Rivarola, J. Huang, P. K. Nayak, J. B. Patel, H. A. Mohd Yusof, Y. Vaynzof, R. Zhu, I. Ramirez, J. Zhang, C. Ducati, C. Grovenor, M. B. Johnston, D. S. Ginger, R. J. Nicholas, H. J. Snaith, Energ. Environ. Sci. 2016, 9, 2892.

[34] S. R. Johnson, T. Tiedje, Journal of Applied Physics 1995, 78, 5609.

[35] M. A. Green, Solar Cells 1982, 7, 337.

[36] P. K. Nayak, G. Garcia-Belmonte, A. Kahn, J. Bisquert, D. Cahen, Energ. Environ. Sci. 2012, 5, 6022 .

[37] S. Rühle, Sol. Energy 2016, 130, 139.

[38] M. A. Green, Y. Hishikawa, W. Warta, E. D. Dunlop, D. H. Levi, J. Hohl-Ebinger, A. W. H. Ho-Baillie, Prog. Photovoltaics 2017, 25, 668.

[39] X. Zheng, B. Chen, J. Dai, Y. Fang, Y. Bai, Y. Lin, H. Wei, Xiao C. Zeng, J. Huang, Nat. Energy 2017, 2, 17102.

[40] D. Luo, W. Yang, Z. Wang, A. Sadhanala, Q. Hu, R. Su, R. Shivanna, G. F. Trindade, J. F. Watts, Z. Xu, T. Liu, K. Chen, F. Ye, P. Wu, L. Zhao, J. Wu, Y. Tu, Y. Zhang, X. Yang, W. Zhang, R. H. Friend, Q. Gong, H. J. Snaith, R. Zhu, Science 2018, 360, 1442. 


\section{WILEY-VCH}

[41] H. Tan, A. Jain, O. Voznyy, X. Lan, F. P. G. d. Arquer, J. Z. Fan, R. Quintero-

Bermudez, M. Yuan, B. Zhang, Y. Zhao, F. Fan, P. Li, L. N. Quan, Y. Zhao, Z.-H. Lu, Z. Yang, S. Hoogland, E. H. Sargent, Science 2017, 355, 722.

[42] H. Tan, F. Che, M. Wei, Y. Zhao, M. I. Saidaminov, P. Todorović, D. Broberg, G.

Walters, F. Tan, T. Zhuang, B. Sun, Z. Liang, H. Yuan, E. Fron, J. Kim, Z. Yang, O. Voznyy, M. Asta, E. H. Sargent, Nat. Commun. 2018, 9, 3100.

[43] W.-J. Yin, T. Shi, Y. Yan, Applied Physics Letters 2014, 104, 063903.

[44] C. Eames, J. M. Frost, P. R. F. Barnes, B. C. O’Regan, A. Walsh, M. S. Islam, Nat. Commun. 2015, 6, 7497; A. Walsh, D. O. Scanlon, S. Chen, X. G. Gong, S.-H. Wei, Angewandte Chemie 2015, 127, 1811; J. Kim, S.-H. Lee, J. H. Lee, K.-H. Hong, J. Phys. Chem. Lett. 2014, 5, 1312.

[45] M. L. Agiorgousis, Y.-Y. Sun, H. Zeng, S. Zhang, J. Am. Chem. Soc. 2014, 136, 14570.

[46] S. Yun, X. Zhou, J. Even, A. Hagfeldt, Angew. Chem. Int. Edit. 2017, 56, 15806.

[47] W.-J. Yin, J.-H. Yang, J. Kang, Y. Yan, S.-H. Wei, J. Mater. Chem. A 2015, 3, 8926.

[48] T. A. Berhe, W.-N. Su, C.-H. Chen, C.-J. Pan, J.-H. Cheng, H.-M. Chen, M.-C. Tsai, L.-Y. Chen, A. A. Dubale, B.-J. Hwang, Energ. Environ. Sci. 2016, 9, 323.

[49] T. Bu, X. Liu, Y. Zhou, J. Yi, X. Huang, L. Luo, J. Xiao, Z. Ku, Y. Peng, F. Huang, Y.-B. Cheng, J. Zhong, Energ. Environ. Sci. 2017, 10, 2509.

[50] D.-Y. Son, S.-G. Kim, J.-Y. Seo, S.-H. Lee, H. Shin, D. Lee, N.-G. Park, J. Am. Chem. Soc. 2018, 140, 1358.

[51] M. Abdi-Jalebi, Z. Andaji-Garmaroudi, S. Cacovich, C. Stavrakas, B. Philippe, J. M. Richter, M. Alsari, E. P. Booker, E. M. Hutter, A. J. Pearson, S. Lilliu, T. J. Savenije, H. Rensmo, G. Divitini, C. Ducati, R. H. Friend, S. D. Stranks, Nature 2018, 555, 497.

[52] M. Abdi-Jalebi, Z. Andaji-Garmaroudi, A. J. Pearson, G. Divitini, S. Cacovich, B.

Philippe, H. Rensmo, C. Ducati, R. H. Friend, S. D. Stranks, ACS Energy Lett. 2018, 3, 2671. 


\section{WILEY-VCH}

[53] M. Abdi-Jalebi, M. I. Dar, A. Sadhanala, S. P. Senanayak, M. Franckevičius, N.

Arora, Y. Hu, M. K. Nazeeruddin, S. M. Zakeeruddin, M. Grätzel, R. H. Friend, Adv. Energy Mater. 2016, 6, 1502472.

[54] J. Navas, A. Sanchez-Coronilla, J. J. Gallardo, N. Cruz Hernandez, J. C. Pinero, R.

Alcantara, C. Fernandez-Lorenzo, D. M. De los Santos, T. Aguilar, J. Martin-Calleja, Nanoscale 2015, 7, 6216.

[55] M. I. Saidaminov, J. Kim, A. Jain, R. Quintero-Bermudez, H. Tan, G. Long, F. Tan, A. Johnston, Y. Zhao, O. Voznyy, E. H. Sargent, Nat. Energy 2018, 3, 648.

[56] X. Gong, L. Guan, H. Pan, Q. Sun, X. Zhao, H. Li, H. Pan, Y. Shen, Y. Shao, L. Sun, Z. Cui, L. Ding, M. Wang, Adv. Func. Mater., 0, 1804286.

[57] H. Tsai, R. Asadpour, J.-C. Blancon, C. C. Stoumpos, O. Durand, J. W. Strzalka, B. Chen, R. Verduzco, P. M. Ajayan, S. Tretiak, J. Even, M. A. Alam, M. G. Kanatzidis, W. Nie, A. D. Mohite, Science 2018, 360, 67; E. Mosconi, D. Meggiolaro, H. J. Snaith, S. D. Stranks, F. De Angelis, Energ. Environ. Sci. 2016, 9, 3180.

[58] G. E. Eperon, D. Moerman, D. S. Ginger, ACS Nano 2016, 10, 10258.

[59] M. De Bastiani, E. Aydin, T. Allen, D. Walter, A. Fell, J. Peng, N. Gasparini, J. Troughton, D. Baran, K. Weber, T. P. White, S. De Wolf, Adv. Electron. Mater. 2018, 0, 1800500.

[60] Q. Chen, H. Zhou, T.-B. Song, S. Luo, Z. Hong, H.-S. Duan, L. Dou, Y. Liu, Y. Yang, Nano Lett. 2014, 14, 4158.

[61] J. Song, E. Zheng, J. Bian, X.-F. Wang, W. Tian, Y. Sanehira, T. Miyasaka, J. Mater. Chem. A 2015, 3, 10837; L. Wang, C. McCleese, A. Kovalsky, Y. Zhao, C. Burda, J. Am. Chem. Soc. 2014, 136, 12205, 12205; B.-w. Park, N. Kedem, M. Kulbak, D. Y. Lee, W. S. Yang, N. J. Jeon, J. Seo, G. Kim, K. J. Kim, T. J. Shin, G. Hodes, D. Cahen, S. I. Seok, Nat. Commun. 2018, 9, 3301. 


\section{WILEY-VCH}

[62] T. J. Jacobsson, J.-P. Correa-Baena, E. H. Anaraki, B. Philippe, S. D. Stranks, M. E. F. Bouduban, W. Tress, K. Schenk, J. Teuscher, J.-E. Moser, H. Rensmo, A. Hagfeldt, J. Am. Chem. Soc. 2016, 138, 10331.

[63] J. Holovský, S. De Wolf, J. Werner, Z. Remeš, M. Müller, N. Neykova, M. Ledinský, L. Černá, P. Hrzina, P. Löper, B. Niesen, C. Ballif, J. Phys. Chem. Lett. 2017, 8, 838.

[64] Q. Jiang, Z. Chu, P. Wang, X. Yang, H. Liu, Y. Wang, Z. Yin, J. Wu, X. Zhang, J. You, Adv. Mater. 2017, 1703852.

[65] D.-Y. Son, J.-W. Lee, Y. J. Choi, I.-H. Jang, S. Lee, P. J. Yoo, H. Shin, N. Ahn, M.

Choi, D. Kim, N.-G. Park, Nat. Energy 2016, 1, 16081.

[66] Z. Hawash, S. R. Raga, D.-Y. Son, L. K. Ono, N.-G. Park, Y. Qi, J. Phys. Chem. Lett. 2017, 8, 3947.

[67] K. T. Cho, S. Paek, G. Grancini, C. Roldan-Carmona, P. Gao, Y. Lee, M. K. Nazeeruddin, Energ. Environ. Sci. 2017, 10, 621.

[68] T. Li, Y. Pan, Z. Wang, Y. Xia, Y. Chen, W. Huang, J. Mater. Chem. A 2017, 5, 12602.

[69] X. Li, M. I. Dar, C. Yi, J. Luo, M. Tschumi, S. M. Zakeeruddin, M. K. Nazeeruddin, H. Han, M. Grätzel, Nat. Chemistry 2015, 7, 703.

[70] Y.-Z. Zheng, X.-T. Li, E.-F. Zhao, X.-D. Lv, F.-L. Meng, C. Peng, X.-S. Lai, M. Huang, G. Cao, X. Tao, J.-F. Chen, Journal of Power Sources 2018, 377, 103.

[71] Q. Tai, P. You, H. Sang, Z. Liu, C. Hu, H. L. W. Chan, F. Yan, Nat. Commun. 2016, 7,11105 .

[72] W. Ke, C. Xiao, C. Wang, B. Saparov, H.-S. Duan, D. Zhao, Z. Xiao, P. Schulz, S. P. Harvey, W. Liao, W. Meng, Y. Yu, A. J. Cimaroli, C.-S. Jiang, K. Zhu, M. Al-Jassim, G. Fang, D. B. Mitzi, Y. Yan, Adv. Mater. 2016, 28, 5214.

[73] C. Wang, D. Zhao, Y. Yu, N. Shrestha, C. R. Grice, W. Liao, A. J. Cimaroli, J. Chen, R. J. Ellingson, X. Zhao, Y. Yan, Nano Energy 2017, 35, 223; Y. Yu, C. Wang, C. R. Grice, 


\section{WILEY-VCH}

N. Shrestha, D. Zhao, W. Liao, L. Guan, R. A. Awni, W. Meng, A. J. Cimaroli, K. Zhu, R. J. Ellingson, Y. Yan, ACS Energy Lett. 2017, 2, 1177.

[74] Y. Shao, Z. Xiao, C. Bi, Y. Yuan, J. Huang, Nat. Commun. 2014, 5, 5784.

[75] M. De Bastiani, G. Dell'Erba, M. Gandini, V. D'Innocenzo, S. Neutzner, A. R. S.

Kandada, G. Grancini, M. Binda, M. Prato, J. M. Ball, M. Caironi, A. Petrozza, Adv. Energy Mater. 2016, 6, 1501453.

[76] J. Xu, A. Buin, A. H. Ip, W. Li, O. Voznyy, R. Comin, M. Yuan, S. Jeon, Z. Ning, J. J. McDowell, P. Kanjanaboos, J.-P. Sun, X. Lan, L. N. Quan, D. H. Kim, I. G. Hill, P.

Maksymovych, E. H. Sargent, Nat. Commun. 2015, 6, 7081.

[77] T. Zhao, C.-C. Chueh, Q. Chen, A. Rajagopal, A. K. Y. Jen, ACS Energy Lett. 2016, 1, 757.

[78] S. M. Huber, J. D. Scanlon, E. Jimenez-Izal, J. M. Ugalde, I. Infante, Phys. Chem. Chem. Phys. 2013, 15, 10350.

[79] A. Abate, M. Saliba, D. J. Hollman, S. D. Stranks, K. Wojciechowski, R. Avolio, G. Grancini, A. Petrozza, H. J. Snaith, Nano Lett. 2014, 14, 3247.

[80] N. K. Noel, A. Abate, S. D. Stranks, E. S. Parrott, V. M. Burlakov, A. Goriely, H. J. Snaith, ACS Nano 2014, 8, 9815.

[81] S. T. Birkhold, E. Zimmermann, T. Kollek, D. Wurmbrand, S. Polarz, L. SchmidtMende, Adv. Func. Mater. 2017, 27, 1604995.

[82] Y. Lin, L. Shen, J. Dai, Y. Deng, Y. Wu, Y. Bai, X. Zheng, J. Wang, Y. Fang, H. Wei, W. Ma, X. C. Zeng, X. Zhan, J. Huang, Adv. Mater. 2017, 29, 1604545.

[83] X. Zheng, Y. Deng, B. Chen, H. Wei, X. Xiao, Y. Fang, Y. Lin, Z. Yu, Y. Liu, Q. Wang, J. Huang, Adv. Mater., 2018, 30, 1803428.

[84] D. Song, D. Wei, P. Cui, M. Li, Z. Duan, T. Wang, J. Ji, Y. Li, J. M. Mbengue, Y. Li, Y. He, M. Trevor, N.-G. Park, J. Mater. Chem. A 2016, 4, 6091. 


\section{WILEY-VCH}

[85] J.-F. Lu, X. Lin, X. Jiao, T. R. Gengenbach, A. D. Scully, L. Jiang, B. Tan, J. Sun, B.

Li, N. Pai, u. bach, A. N. Simonov, Y.-B. Cheng, Energ. Environ. Sci. 2018, 11, 1880.

[86] F. Wang, W. Geng, Y. Zhou, H.-H. Fang, C.-J. Tong, M. A. Loi, L.-M. Liu, N. Zhao, Adv. Mater. 2016, 28, 9986.

[87] Z. Yang, W. Feng, C. Yu, W. Jian-Pu, F. Hong-Hua, L. M. Antonietta, Z. Ni, W. Ching-Ping, Adv. Ener. Mater. 2017, 7, 1701048.

[88] C. Sun, Z. Wu, H.-L. Yip, H. Zhang, X.-F. Jiang, Q. Xue, Z. Hu, Z. Hu, Y. Shen, M. Wang, F. Huang, Y. Cao, Adv. Ener. Mater. 2016, 6, 1501534.

[89] X. Fang, J. Ding, N. Yuan, P. Sun, M. Lv, G. Ding, C. Zhu, Phys. Chem. Chem. Phys. 2017, 19, 6057.

[90] H. Li, L. Tao, F. Huang, Q. Sun, X. Zhao, J. Han, Y. Shen, M. Wang, ACS Applied Materials \& Interfaces 2017, 9, 38967.

[91] D. Koushik, W. Verhees, Y. Kuang, S. Veenstra, D. Zhang, M. A. Verheijen, M. Creatore, R. E. I. E. I. Schropp, Energ. Environ. Sci. 2017, 10, 91.

[92] X. Dong, X. Fang, M. Lv, B. Lin, S. Zhang, J. Ding, N. Yuan, J. Mater. Chem. A 2015, 3, 5360.

[93] F. Wang, A. Shimazaki, F. Yang, K. Kanahashi, K. Matsuki, Y. Miyauchi, T.

Takenobu, A. Wakamiya, Y. Murata, K. Matsuda, The Journal of Physical Chemistry C 2017, $121,1562$.

[94] D. Bi, C. Yi, J. Luo, J.-D. Décoppet, F. Zhang, Shaik M. Zakeeruddin, X. Li, A.

Hagfeldt, M. Grätzel, Nat. Energy 2016, 1, 16142.

[95] F. Yang, H. E. Lim, F. Wang, M. Ozaki, A. Shimazaki, J. Liu, N. B. Mohamed, K. Shinokita, Y. Miyauchi, A. Wakamiya, Y. Murata, K. Matsuda, Adv. Mater. Interfaces 2017, 1701256. 


\section{WILEY-VCH}

[96] J. Peng, J. I. Khan, W. Liu, E. Ugur, T. Duong, Y. Wu, H. Shen, K. Wang, H. Dang, E. Aydin, X. Yang, Y. Wan, K. J. Weber, K. R. Catchpole, F. Laquai, S. Wolf, T. P. White, Adv. Energy Mater. 2018, 0, 1801208.

[97] B. Chaudhary, A. Kulkarni, A. K. Jena, M. Ikegami, Y. Udagawa, H. Kunugita, K. Ema, T. Miyasaka, ChemSusChem 2017, 10, 2473.

[98] L. Zuo, H. Guo, D. W. deQuilettes, S. Jariwala, N. De Marco, S. Dong, R. DeBlock, D. S. Ginger, B. Dunn, M. Wang, Y. Yang, Science Adv. 2017, 3, e1700106.

[99] M. Li, X. Yan, Z. Kang, Y. Huan, Y. Li, R. Zhang, Y. Zhang, ACS Applied Materials \& Interfaces 2018; Q. Wang, Q. Dong, T. Li, A. Gruverman, J. Huang, Adv. Mater. 2016, 28, 6734.

[100] M. Kim, S. G. Motti, R. Sorrentino, A. Petrozza, Energ. Environ. Sci. 2018, 11, 2609.

[101] J. Calabrese, N. L. Jones, R. L. Harlow, N. Herron, D. L. Thorn, Y. Wang, J. Am. Chem. Soc. 1991, 113, 2328.

[102] H. Tsai, W. Nie, J.-C. Blancon, C. C. Stoumpos, R. Asadpour, B. Harutyunyan, A. J. Neukirch, R. Verduzco, J. J. Crochet, S. Tretiak, L. Pedesseau, J. Even, M. A. Alam, G. Gupta, J. Lou, P. M. Ajayan, M. J. Bedzyk, M. G. Kanatzidis, A. D. Mohite, Nature 2016, 536,312 .

[103] J. Chen, J.-Y. Seo, N.-G. Park, dv. Energy Mater. 2018, 1702714.

[104] B. Yang, X. Shuang, H. Chen, Z. Teng, M. Xiangyue, L. He, Y. Yinglong, Y. Shihe, Adv. Energy Mater. 2017, 7, 1701038; L. Nan, Z. Zonglong, C. Chu-Chen, L. Hongbin, P. Bo, P. Alessio, L. Xiaosong, W. Liduo, J. A. K.-Y., Adv. Energy Mater. 2017, 7, 1601307. [105] D. S. Lee, J. S. Yun, J. Kim, A. M. Soufiani, S. Chen, Y. Cho, X. Deng, J. Seidel, S. Lim, S. Huang, A. W. Y. Ho-Baillie, ACS Energy Lett. 2018, 3, 647.

[106] G. Grancini, C. Roldán-Carmona, I. Zimmermann, E. Mosconi, X. Lee, D. Martineau, S. Narbey, F. Oswald, F. De Angelis, M. Graetzel, M. K. Nazeeruddin, Nat. Commun. 2017, 8,15684 . 


\section{WILEY-VCH}

[107] Z. Wang, Q. Lin, F. P. Chmiel, N. Sakai, L. M. Herz, H. J. Snaith, Nat. Energy 2017, 2, 17135 .

[108] C. Yongyoon, S. A. Mahboubi, Y. J. Sung, K. Jincheol, L. D. Seul, S. Jan, D. Xiaofan,

G. M. A., H. Shujuan, H. B. A. W. Y., Adv. Energy Mater., 2018, 0, 1703392.

[109] M. Jung, T. J. Shin, J. Seo, G. Kim, S. I. Seok, Energ. Environ. Sci. 2018, 11, 2188.

[110] G. Grancini, M. K. Nazeeruddin, Nat. Rev. Mater., 2019, 4, 4.

[111] J. Peng, Y. Wu, W. Ye, D. A. Jacobs, H. Shen, X. Fu, Y. Wan, T. Duong, N. Wu, C. Barugkin, H. T. Nguyen, D. Zhong, J. Li, T. Lu, Y. Liu, M. N. Lockrey, K. J. Weber, K. R. Catchpole, T. P. White, Energ. Environ. Sci. 2017, 10, 1792.

[112] J. Cao, B. Wu, R. Chen, Y. Wu, Y. Hui, B.-W. Mao, N. Zheng, Adv. Mater. 2018, 1705596.

[113] A. Kojima, K. Teshima, Y. Shirai, T. Miyasaka, J. Am. Chem. Soc. 2009, 131, 6050.

[114] J.-H. Im, C.-R. Lee, J.-W. Lee, S.-W. Park, N.-G. Park, Nanoscale 2011, 3, 4088.

[115] J. M. Ball, M. M. Lee, A. Hey, H. J. Snaith, Energy Environ. Sci. 2013, 6, 1739.

[116] W. S. Yang, B.-W. Park, E. H. Jung, N. J. Jeon, Y. C. Kim, D. U. Lee, S. S. Shin, J.

Seo, E. K. Kim, J. H. Noh, S. I. Seok, Science 2017, 356, 1376.

[117] D. Yang, X. Zhou, R. Yang, Z. Yang, W. Yu, X. Wang, C. Li, S. F. Liu, R. P. Chang, Energy Environ. Sci. 2016, 9, 3071.

[118] H. Tan, A. Jain, O. Voznyy, X. Lan, F. P. G. de Arquer, J. Z. Fan, R. QuinteroBermudez, M. Yuan, B. Zhang, Y. Zhao, Science 2017, 355, 722.

[119] Z. Liang, Q. Zhang, L. Jiang, G. Cao, Energy Environ. Sci. 2015, 8, 3442.

[120] J. P. Correa-Baena, L. Steier, W. Tress, M. Saliba, S. Neutzner, T. Matsui, F.

Giordano, T. J. Jacobsson, A. R. S. Kandada, S. M. Zakeeruddin, Energy Environ. Sci. 2015, $8,2928$.

[121] Q. Jiang, L. Zhang, H. Wang, X. Yang, J. Meng, H. Liu, Z. Yin, J. Wu, X. Zhang, J. You, Nat. Energy 2016, 2, 16177. 


\section{WILEY-VCH}

[122] S.-H. Turren-Cruz, M. Saliba, M. T. Mayer, H. Juarez-Santiesteban, X. Mathew, L.

Nienhaus, W. Tress, M. P. Erodici, M.-J. Sher, M. G. Bawendi, M. Gratzel, A. Abate, A. Hagfeldt, J.-P. Correa-Baena, Energy Environ. Sci. 2018, 11, 78.

[123] E. H. Anaraki, A. Kermanpur, L. Steier, K. Domanski, T. Matsui, W. Tress, M. Saliba, A. Abate, M. Grätzel, A. Hagfeldt, Energy Environ. Sci. 2016, 9, 3128.

[124] D. Yang, R. Yang, K. Wang, C. Wu, X. Zhu, J. Feng, X. Ren, G. Fang, S. Priya, S. Liu, Nat. Commun. 2018, 9, 3239.

[125] C. Tao, J. Van Der Velden, L. Cabau, N. F. Montcada, S. Neutzner, S. Kandada, A. Ram, S. Marras, L. Brambilla, M. Tommasini, Adv. Mater. 2017, 29.

[126] C. Wei, W. Yinghui, F. Jing, D. A. B., L. Fangzhou, T. H. Won, N. Annie, S. Charles, C. W. Kin, W. Dong, H. Zhu-Bing, Adv. Energy Mater. 2018, 0, 1703519.

[127] E. Aydin, J. Troughton, M. De Bastiani, E. Ugur, M. Sajjad, A. Alzahrani, M.

Neophytou, U. Schwingenschlögl, F. Laquai, D. Baran, S. De Wolf, ACS Appl. Energy Mater. 2018, 11, 6227.

[128] Y. Chen, Z. Yang, S. Wang, X. Zheng, Y. Wu, N. Yuan, W.-H. Zhang, S. Liu, Adv. Mater. 2018, 0, 1805660.

[129] T. Duong, J. Peng, D. Walter, J. Xiang, H. Shen, D. Chugh, M. Lockrey, D. Zhong, J. Li, K. Weber, T. P. White, K. R. Catchpole, ACS Energy Lett. 2018, 2441.

[130] M. M. Lee, J. Teuscher, T. Miyasaka, T. N. Murakami, H. J. Snaith, Science 2012, $338,643$.

[131] J. Burschka, N. Pellet, S.-J. Moon, R. Humphry-Baker, P. Gao, M. K. Nazeeruddin, M. Grätzel, Nature 2013, 499, 316.

[132] N. J. Jeon, J. H. Noh, Y. C. Kim, W. S. Yang, S. Ryu, S. I. Seok, Nat. Mater. 2014, $13,897$.

[133] N. J. Jeon, J. H. Noh, W. S. Yang, Y. C. Kim, S. Ryu, J. Seo, S. I. Seok, Nature 2015, $517,476$. 


\section{WILEY-VCH}

[134] M. Liu, M. B. Johnston, H. J. Snaith, Nature 2013, 501, 395.

[135] C.-H. Chiang, Z.-L. Tseng, C.-G. Wu, J. Mater. Chem. A 2014, 2, 15897.

[136] J. H. Heo, H. J. Han, D. Kim, T. K. Ahn, S. H. Im, Energy Environ. Sci. 2015, 8, 1602.

[137] C.-H. Chiang, M. K. Nazeeruddin, M. Grätzel, C.-G. Wu, Energy Environ. Sci. 2017.

[138] C. Bi, Q. Wang, Y. Shao, Y. Yuan, Z. Xiao, J. Huang, Nat. Commun., 2015.

[139] W. Qi, D. Qingfeng, L. Tao, G. Alexei, H. Jinsong, Adv. Mater. 2016, 28, 6734.

[140] S. Chavhan, O. Miguel, H.-J. Grande, V. Gonzalez-Pedro, R. S. Sánchez, E. M. Barea, I. Mora-Seró, R. Tena-Zaera, J. Mater. Chem. A 2014, 2, 12754.

[141] S. Ye, W. Sun, Y. Li, W. Yan, H. Peng, Z. Bian, Z. Liu, C. Huang, Nano Lett. 2015, 15,3723 .

[142] M. Jung, Y. C. Kim, N. J. Jeon, W. S. Yang, J. Seo, J. H. Noh, S. I. Seok, ChemSusChem 2016, 9, 2592.

[143] N. Arora, M. I. Dar, A. Hinderhofer, N. Pellet, F. Schreiber, S. M. Zakeeruddin, M. Grätzel, Science 2017, 358, 768.

[144] K.-C. Wang, P.-S. Shen, M.-H. Li, S. Chen, M.-W. Lin, P. Chen, T.-F. Guo, ACS Applied Materials \& Interfaces 2014, 6, 11851.

[145] J. W. Jung, C. C. Chueh, A. K. Y. Jen, Adv. Mater. 2015, 27, 7874.

[146] W. C. Yi Hou, D. Baran, T. Stubhan, N. A. Luechinger, B. Hartmeier, M. Richter, J. Min, S. Chen, C. O. R. Quiroz, N. Li, H. Zhang, T. Heumueller, G. J. Matt, A. Osvet, K. Forberich, Z. Zhang, Y. Li, B. Winter, P. Schweizer, E. Spiecker, C. J. Brabec, Adv. Mater. 2016, 28, 5112.

[147] C. Wei, L. Fang-Zhou, F. Xi-Yuan, D. A. B., C. W. Kin, H. Zhu-Bing, Adv. Energy Mater. 2017, 7, 1700722.

[148] Z. Liu, J. Chang, Z. Lin, L. Zhou, Z. Yang, D. Chen, C. Zhang, S. Liu, Y. Hao, Adv. Energy Mater. 2018, 0, 1703432. 


\section{WILEY-VCH}

[149] X. Pan, M.-Q. Yang, X. Fu, N. Zhang, Y.-J. Xu, Nanoscale 2013, 5, 3601.

[150] K. G. Godinho, A. Walsh, G. W. Watson, J. Phys. Chem. C 2008, 113, 439.

[151] S. K. Pathak, A. Abate, P. Ruckdeschel, B. Roose, K. C. Gödel, Y. Vaynzof, A.

Santhala, S.-I. Watanabe, D. J. Hollman, N. Noel, A. Sepe, U. Wiesner, R. Friend, H. J.

Snaith, U. Steiner, Adv. Func. Mater. 2014, 24, 6046.

[152] M. Vasilopoulou, D. G. Georgiadou, A. Soultati, N. Boukos, S. Gardelis, L. C. Palilis,

M. Fakis, G. Skoulatakis, S. Kennou, M. Botzakaki, S. Georga, C. A. Krontiras, F. Auras, D. Fattakhova-Rohlfing, T. Bein, T. A. Papadopoulos, D. Davazoglou, P. Argitis, Adv. Energy Mater. 2014, 4, 1400214.

[153] Y. Shao, Y. Yuan, J. Huang, Nat. Energy 2016, 1, 15001.

[154] J. Peng, X. Zhou, H. Shen, Y. Wu, H. K. Mulmudi, Y. Wan, D. Zhong, J. Li, T.

Tsuzuki, K. J. Weber, K. R. Catchpole, T. P. White, Adv. Energy Mater. 2017, 7, 1601768.

[155] M. M. Islam, T. Bredow, A. Gerson, Phys. Rev. B 2007, 76, 045217.

[156] R. Shirley, M. Kraft, O. R. Inderwildi, Phys. Rev. B 2010, 81, 075111.

[157] M. Li, Y. Huan, X. Yan, Z. Kang, Y. Guo, Y. Li, X. Liao, R. Zhang, Y. Zhang, ChemSusChem, 2018, 11, 171.

[158] F. Giordano, A. Abate, J. P. Correa Baena, M. Saliba, T. Matsui, S. H. Im, S. M. Zakeeruddin, M. K. Nazeeruddin, A. Hagfeldt, M. Graetzel, Nat. Commun. 2016, 7, 10379.

[159] A. Abrusci, S. D. Stranks, P. Docampo, H.-L. Yip, A. K.-Y. Jen, H. J. Snaith, Nano Lett. 2013, 13, 3124.

[160] K. Wojciechowski, S. D. Stranks, A. Abate, G. Sadoughi, A. Sadhanala, N. Kopidakis, G. Rumbles, C.-Z. Li, R. H. Friend, A. K.-Y. Jen, ACS Nano 2014, 8, 12701.

[161] L. Zuo, Z. Gu, T. Ye, W. Fu, G. Wu, H. Li, H. Chen, J. Am. Chem. Soc. 2015, 137, 2674.

[162] L. Zuo, Q. Chen, N. De Marco, Y.-T. Hsieh, H. Chen, P. Sun, S.-Y. Chang, H. Zhao, S. Dong, Y. Yang, Nano Lett. 2017, 17, 269. 


\section{WILEY-VCH}

[163] Y. H. Lee, J. Luo, M.-K. Son, P. Gao, K. T. Cho, J. Seo, S. M. Zakeeruddin, M.

Grätzel, M. K. Nazeeruddin, Adv. Mater. 2016, 28, 3966.

[164] G. S. Han, H. S. Chung, B. J. Kim, D. H. Kim, J. W. Lee, B. S. Swain, K. Mahmood,

J. S. Yoo, N.-G. Park, J. H. Lee, H. S. Jung, J. Mater. Chem. A 2015, 3, 9160.

[165] S. F. Shaikh, H.-C. Kwon, W. Yang, H. Hwang, H. Lee, E. Lee, S. Ma, J. Moon, J. Mater. Chem. A 2016, 4, 15478.

[166] J. Y. Seo, R. Uchida, H. S. Kim, Y. Saygili, J. Luo, C. Moore, J. Kerrod, A. Wagstaff, M. Eklund, R. McIntyre, Adv. Func. Mater. 2018, 28, 1705763.

[167] L. Xu, Z. Yuanfang, S. Lei, L. Ziheng, H. Jialiang, Y. J. Sung, Z. Yiyu, P. Aobo, S. Kaiwen, H. Ziv, S. J. A., S. Jan, G. M. A., H. Xiaojing, Adv. Energy Mater. 2018, 0, 1800138. [168] K.-G. Lim, H.-B. Kim, J. Jeong, H. Kim, J. Y. Kim, T.-W. Lee, Adv. Mater. 2014, 26, 6461; B. Li, C. Zheng, H. Liu, J. Zhu, H. Zhang, D. Gao, W. Huang, ACS Applied Materials \& Interfaces 2016, 8, 27438; Q. Xue, G. Chen, M. Liu, J. Xiao, Z. Chen, Z. Hu, X.-F. Jiang, B. Zhang, F. Huang, W. Yang, H.-L. Yip, Y. Cao, Adv. Energy Mater. 2016, 6, 1502021; Z.K. Wang, X. Gong, M. Li, Y. Hu, J.-M. Wang, H. Ma, L.-S. Liao, ACS Nano 2016, 10, 5479; Z. Gu, L. Zuo, T. T. Larsen-Olsen, T. Ye, G. Wu, F. C. Krebs, H. Chen, J. Mater. Chem. A 2015, 3, 24254.

[169] C. J. Flynn, S. M. McCullough, E. Oh, L. Li, C. C. Mercado, B. H. Farnum, W. Li, C. L. Donley, W. You, A. J. Nozik, J. R. McBride, T. J. Meyer, Y. Kanai, J. F. Cahoon, ACS Applied Materials \& Interfaces 2016, 8, 4754.

[170] Y. Bai, H. Chen, S. Xiao, Q. Xue, T. Zhang, Z. Zhu, Q. Li, C. Hu, Y. Yang, Z. Hu, F. Huang, K. S. Wong, H.-L. Yip, S. Yang, Adv. Func. Mater. 2016, 26, 2950; Q. Xue, Y. Bai, M. Liu, R. Xia, Z. Hu, Z. Chen, X.-F. Jiang, F. Huang, S. Yang, Y. Matsuo, H.-L. Yip, Y. Cao, Adv. Energy Mater. 2017, 7, 1602333.

[171] X. Yang, E. Aydin, H. Xu, J. Kang, M. Hedhili, W. Liu, Y. Wan, J. Peng, C.

Samundsett, A. Cuevas, S. Wolf, Adv. Energy Mater. 2018, 8, 1800608. 


\section{WILEY-VCH}

\section{Author Biographies}

Erkan Aydin earned his M.Sc. (2012) and Ph.D. (2016) degree in Micro and Nanotechnology Program from TOBB University of Economics and Technology, Ankara, Turkey. During his M.Sc. and Ph.D. period, he has focused on the process development for cost-efficient and environmentally friendly fabrication of copper indium gallium sulfide (selenide) CIGS(Se)based thin film solar cells. Since 2016 he has been working on perovskite-silicon tandem solar cells at the King Abdullah University of Science and Technology (KAUST) Solar Center, Jeddah, KSA. His expertise lies in the process development and advanced characterization of the high-efficiency perovskite solar cells for perovskite-based tandem solar cells by exploring thin films and engineering interfaces and contacts.

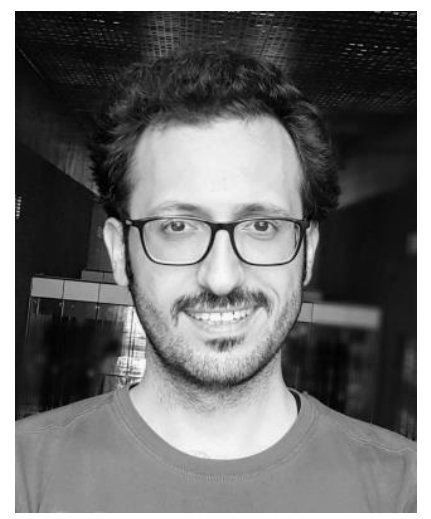

Michele De Bastiani obtained the M.Sc. (2011) in Material Science at the Universita' degli Studi di Padova and the Ph.D. (2016) in the School of Material Science and Engineering of the Universita' degli Studi di Padova, in co-tutelage with the Center for Nanoscience and Technology (CNST) of the Istituto Italiano di Tecnologia, in Milan, Italy. After the Ph.D. he joined the King Abdullah University of Science and Technology (KAUST), Jeddah, KSA. Michele's works focus the phenomenon of hysteresis in perovskite solar cells, particularly ions migration and their interaction with electron transport layers. Currently, he is working on the development of high-efficiency perovskite-silicon tandem devices. Michele was recently awarded the ENI award: "Young researcher of the year 2018".

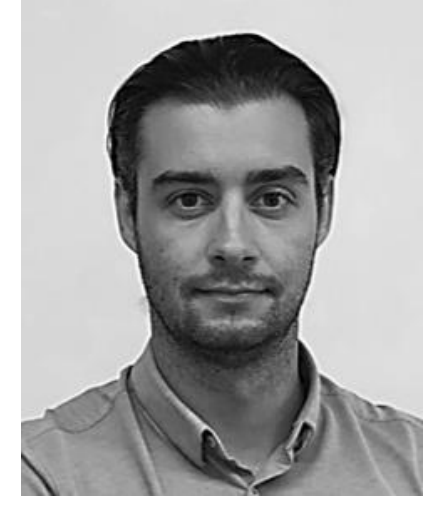

Stefaan De Wolf received his Ph.D. degree in 2005 from the Katholieke Universiteit Leuven in Belgium, during which time he was also affiliated with imec in Belgium, working on crystalline silicon solar cells. From 2005 to 2008, he was with the National Institute of Advanced Industrial Science and Technology (AIST), Tsukuba, Japan, investigating silicon heterojunction structures and devices. In 2008, he joined the Photovoltaics and Thin-Film Electronics Laboratory, Ecole Polytechnique Federale de Lausanne (EPFL), Neuchatel, 


\section{WILEY-VCH}

Switzerland, as a team leader for its activities on high-efficiency silicon solar cells. Since September 2016 he is an associate professor at the King Abdullah University of Science and Technology (KAUST) in Saudi Arabia.

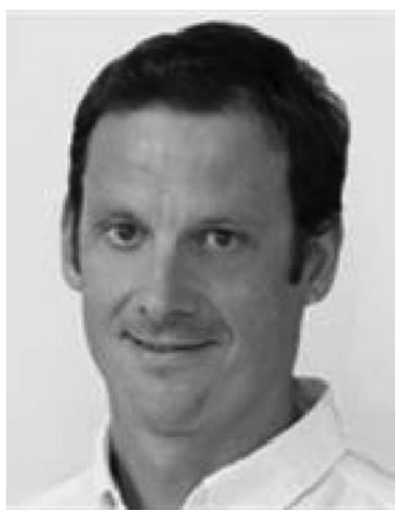




\section{WILEY-VCH}

\section{The table of content}

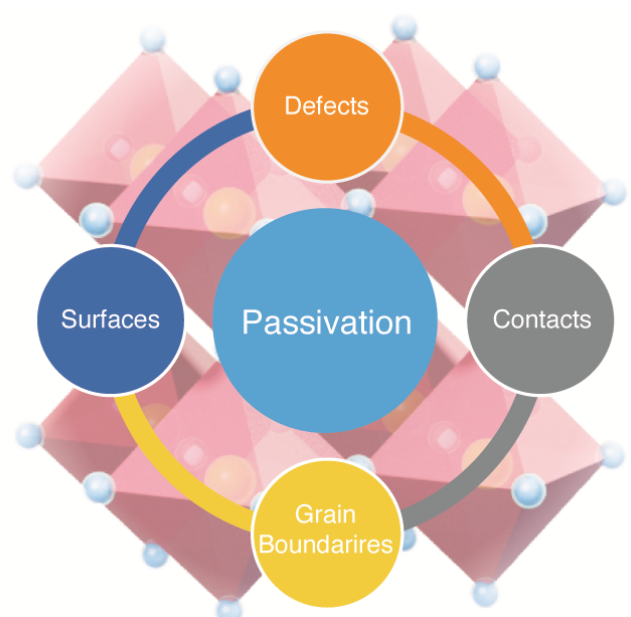

Defects in metal halide perovskites contribute to non-radiative recombination of photocarriers. On device level, such recombination undesirably inflates the open-circuit voltage deficit and acts as a significant roadblock towards the theoretical efficiency limit of $30 \%$ perovskite solar cells. In this review, such voltage-limiting mechanisms have been assessed by focusing on their origin and possible mitigation strategies. 